\title{
THE ROLE OF POSITIVE SCHEMAS IN CHILD PSYCHOPATHOLOGY AND RESILIENCE
}

\author{
A Thesis \\ Presented to \\ The Faculty of Graduate Studies \\ of \\ The University of Guelph \\ by \\ LINDSEY KEYFITZ
}

In partial fulfilment of requirements

for the degree of

Master of Arts

August, 2010

(C) Lindsey Keyfitz, 2010 
Library and Archives

Canada

Published Heritage

Branch

395 Wellington Street

Ottawa ON K1A ON4

Canada
Bibliotheque et

Archives Canada

Direction du

Patrimoine de l'édition

395, rue Wellington

Ottawa ON K1A ON4

Canada
Your file Votre reférence

ISBN: 978-0-494-67490-1

Our file Notre référence

ISBN: 978-0-494-67490-1
NOTICE:

The author has granted a nonexclusive license allowing Library and Archives Canada to reproduce, publish, archive, preserve, conserve, communicate to the public by telecommunication or on the Internet, loan, distribute and sell theses worldwide, for commercial or noncommercial purposes, in microform, paper, electronic and/or any other formats.

The author retains copyright ownership and moral rights in this thesis. Neither the thesis nor substantial extracts from it may be printed or otherwise reproduced without the author's permission.
AVIS:

L'auteur a accordé une licence non exclusive permettant à la Bibliothèque et Archives Canada de reproduire, publier, archiver, sauvegarder, conserver, transmettre au public par télécommunication ou par l'Internet, prêter, distribuer et vendre des thèses partout dans le monde, à des fins commerciales ou autres, sur support microforme, papier, électronique et/ou autres formats.

L'auteur conserve la propriété du droit d'auteur et des droits moraux qui protège cette thèse. Ni la thèse ni des extraits substantiels de celle-ci ne doivent être imprimés ou autrement reproduits sans son autorisation.
In compliance with the Canadian Privacy Act some supporting forms may have been removed from this thesis.

While these forms may be included in the document page count, their removal does not represent any loss of content from the thesis.
Conformément à la loi canadienne sur la protection de la vie privée, quelques formulaires secondaires ont été enlevés de cette thèse.

Bien que ces formulaires aient inclus dans la pagination, il n'y aura aucun contenu manquant. 


\title{
ABSTRACT
}

\section{THE ROLE OF POSITIVE SCHEMAS IN CHILD PSYCHOPATHOLOGY}

\author{
AND RESILIENCE
}

Lindsey Keyfitz

University of Guelph, 2010
Advisor:

Dr. Margaret Lumley

Cognitive models of vulnerability have yet to integrate positive schemas into models of child psychopathology. This study presents the Positive Schema Questionnaire (PSQ) for youth, and evaluates relations of positive schema themes to depression, anxiety, and resilience. Adolescent boys $(n=84)$ and girls $(n=88)$, aged 9 to $14(M=11.44)$, completed the PSQ, and measures of negative schemas, depression, anxiety, and resilience. Exploratory factor analyses of the PSQ supported a five-factor structure including themes of: Self-Efficacy, Optimism, Interpersonal Trust, Success, and Worthiness. The PSQ appears to be a promising tool, and predicted additional variance in depression, anxiety, and resilience, beyond negative schemas. Furthermore, the content specificity model as envisioned for negative schemas, was found to apply to positive schemas, with themes of Worthiness most predictive of depression and Self-Efficacy most predictive of anxiety and resilience. Findings have implications for incorporating positive schemas into cognitive models of psychopathology. 


\section{Acknowledgements}

I would sincerely like to thank the many people who supported me throughout the process of completing my thesis. Firstly, I would like to thank my supervisor, Dr. Margaret Lumley for her support, guidance, and for always challenging me to explore new ideas. I would like to thank my committee member, Dr. Karl Hennig for his insightful feedback and especially for his help with measure development. I would also like to express my gratitude to Dr. Stephen Lewis for chairing my defense.

I am very thankful to all of the research assistants involved in the Resilient Youth Research group who played a very important role in data collection and were also extremely helpful in the development of the items for the PSQ.

My experience of completing my masters would not have been the same without my classmates. Thank you all for your constant encouragement, advice, laughter and most importantly, for your friendship over the past two years.

Lastly, thank you to my friends at home for always being there for me, and to my family for their constant, unconditional love, support and encouragement. I can't thank you enough, Adam for always keeping me grounded, providing me with an optimistic perspective, and for making me smile even in the most stressful times. 


\section{Table of Contents}

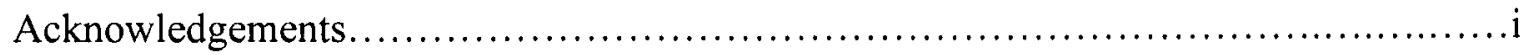

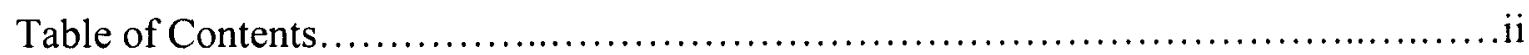

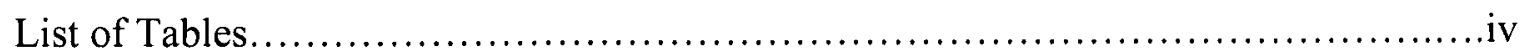

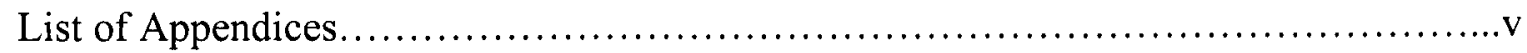

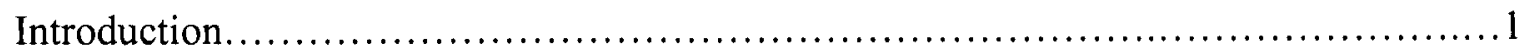

Current Cognitive Models of Child Psychopathology.............................1

Unique Contribution of Positive Schemas............................................................

Positive Schema Questionnaire.............................................. 7

Positive Schemas and Depression............................................ 8

Positive Schemas and Anxiety...............................................12

Positive Schemas and Resilience...........................................16

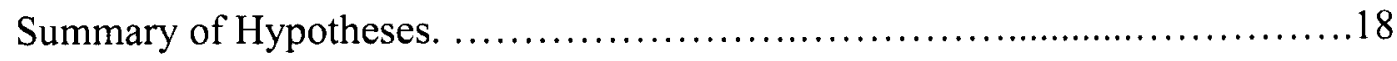

Method................................................................................

Participants.................................................................. 19

Measures.................................................................. 19

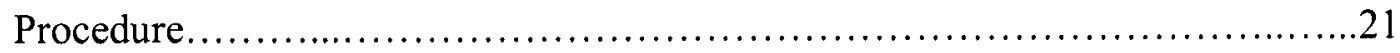

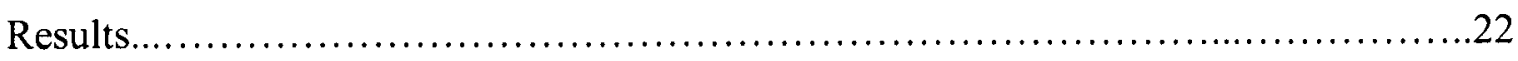

Development of the Positive Schema Questionnaire ...........................22

Descriptive Characteristics.............................................24

Positive Schemas and Depression..........................................29

Positive Schemas and Anxiety............................................. 32

Positive Schemas and Resilience..........................................36 


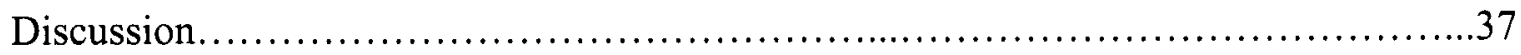

Positive Schema Questionnaire...............................................38

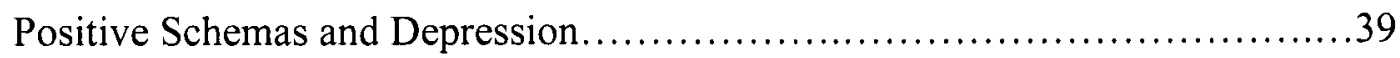

Positive Schemas and Anxiety ............................................41

Positive Schemas and Resilience...........................................43

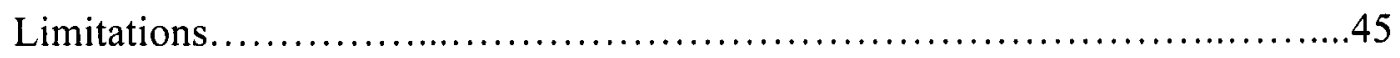

Conclusions........................................................................ 47

References...................................................................... 50

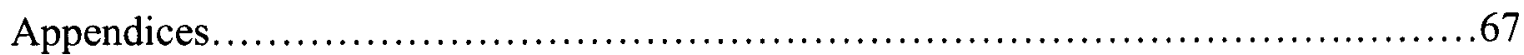


List of Tables

Table 1: Factor Loadings for Varimax Orthogonal Five-Factor Solution................25

Table 2: Descriptive Statistics Means and Standard Deviations...........................27

Table 3: Correlation for Positive Schema Total and Positive Schema Themes

Compared to Outcomes..........................................................30

Table 4: Hierarchical Regression assessing the impact of Positive Schemas above Negative Schemas........................................................ 31

Table 5: Total Effects of Self-Efficacy, Success, Trust, Optimism, and Worthiness on Depression, Anxiety, and Resilience Scores, Estimated through Simultaneous

Regression.......................................................... 33 


\section{List of Appendices}

Appendix A: Positive Schema Questionnaire

Appendix B: Schema Questionnaire for Children

Appendix C: Multidimensional Anxiety Scale for Children

Appendix D: Children's Depression Inventory

Appendix E: Resilience Scale

Appendix F: Consent Form 
The Role of Positive Schemas in Child Psychopathology and Resilience Research on child psychopathology focuses almost exclusively on the role of negative schemas as a vulnerability factor, while there has been a neglect of research on the role of positive schemas in child psychopathology (MacLeod \& Moore, 2000). While decades of research have established negative cognitive schemas as a potent vulnerability factor for various negative developmental outcomes (e.g., Abela \& Hankin, 2008), cognitive models of child psychopathology have yet to fully integrate positive schemas as a potential vulnerability factor. The little research conducted on positive schemas to date, suggests they bear more attention in this regard (e.g., Jaenicke, Hammen, Zupan, Hiroto, Gordon, Adrian, \& Burge, 1987; Prieto, Cole, \& Tageson, 1992; Shirk, Boergers, Easton, \& Van horn, 1998). These studies, however, only focus on positive states on a broad level across all content domains, and thus may gloss over important information regarding how specific schema themes are related to various forms of psychopathology or wellbeing. Part of the reason for the neglect of research on specific positive schema themes is due to the lack of a proper tool to measure these constructs. As such, the goal of the current study is to develop a deeper understanding of the role of positive schema themes by developing a positive schema questionnaire for children, and evaluating how positive schemas of various themes relate to depression, anxiety, and resilience in early adolescence.

Current Cognitive Models of Child Psychopathology

Cognitive theories of psychopathology typically focus on maladaptive cognitive processes as a central vulnerability factor (e.g., Beck, 1967; Young, Klosko, \& Weishaar, 2003). Specifically, many theories focus on negative cognitive schemas as central to 
models of psychopathology. Schemas are defined as mental structures that guide the interpretation, categorization and evaluation of one's experiences (James, Reichelt, Freeston, \& Barton, 2007; Schmidt, Schmidt, \& Young, 1999) and are sometimes referred to as "filters," as they guide the way in which information is interpreted and absorbed (Kendall \& MacDonald, 1993).

Beck's $(1967,1983)$ influential model of psychopathology posits that maladaptive schemas develop in early childhood, and when triggered by a negative life event, result in the processing of information in a way consistent with a child's schema. Furthermore, Beck's content-specificity hypothesis notes that the specific content of one's schemas are important in determining various developmental outcomes (Beck, 1976; Beck, Rush, Shaw, \& Emery, 1979). For example, a person will be vulnerable for depression when possessing "depressogenic" schemas, or dysfunctional attitudes that revolve around themes of loss and deprivation (Beck, 1967; 1983). Once activated, depressogenic schemas negatively bias processing of information and result in the development of negative views of one's self, the world, and the future. Similarly, one will be vulnerable to developing anxiety when he/she possesses schema themes related to harm and danger (Beck \& Clark, 1988; Beck, Emery, \& Greenberg, 1985).

Young (1999; Young et al., 2003) elaborated on Beck's theories by focusing on factors implicated in schema development. He proposed that a child's early experiences impact the development of core beliefs, resulting in the development of "Early Maladaptive Schemas" (EMS), or "self-defeating emotional and cognitive patterns that begin early in our development and repeat throughout life." Young proposes 18 schema themes, each of which are theorized to result from a specific childhood experience. For 
example, among these themes are schemas of Abandonment/Instability, which result from experiences of abandonment; Mistrust/Abuse, resulting from experiences of abuse; Emotional Deprivation, resulting from neglect; and Defectiveness/Shame, which result from early experiences of rejection. Young's theory suggests that these specific cognitive schema themes play an important role in the diathesis to various forms of psychopathology when triggered by life experiences similar to the initial negative experience.

These cognitive models of psychopathology have been researched extensively and are well supported in child/adolescent samples (See Hankin \& Abela, 2005; Abela \& Hankin, 2008; Lakdawalla, Hankin, \& Mermelstein, 2007 for reviews). Countless studies have demonstrated that negative cognitive content acts as a vulnerability factor for various forms of psychopathology (e.g., Abela, Zinck, Kryger, Zilber, \& Hankin, 2009; Gibb \& Abela, 2008; Harmelen, Jong, Glashouwer, Spinhoven, Pennix, 2010; Kercher, Rapee \& Schniering, 2009; Muris, 2006; Stallard, 2007; Vlierberghe, Timbremont, Braet, \& Basile, 2007). Research has also supported Beck's cognitive content specificity hypothesis, indicating that various schema themes differentially predict various outcomes of psychopathology for youth (e.g., Epkins, 2000; Lewinsohn, Joiner, \& Rohde, 2001; Lumley \& Harkness, 2007; Muris, 2006). Many studies converge to demonstrate that depressive cognitions are related to depressive symptoms, while anxious cognitions are related to anxious symptoms (e.g., Beck, Steer, \& Epstein, 1992; Clark, Beck, \& Stewart, 1990; Clark, Steer, \& Beck, 1994; Greenberg \& Beck, 1989; Jolly, 1993; Lumley and Harkness, 2007; Muris, 2006). For example, research indicates that schema themes of loss and worthlessness mediate relations between childhood adversity and depressive 
symptoms, while themes of danger mediate relations between adversity and anxiety symptoms (Lumley \& Harkness, 2007).

While research on links between negative schemas and psychopathology has contributed a great deal to our understanding of child mental health, research has often exclusively focused on negative schemas, while neglecting positive schemas. Given that recent research has demonstrated the importance of understanding the contributions of positive cognition beyond that of negative cognition alone (MacLeod \& Moore, 2000), the current study is poised to strengthen understanding of child psychopathology by developing a more comprehensive understanding of cognitive risk.

Unique Contribution of Positive Schemas: Positive as a Separate Dimension from Negative

The dearth of research on the role of positive schemas in vulnerability to child psychopathology may in part result from the common conception that positive cognition is simply the inverse of negative cognition (MacLeod \& Moore, 2000). Yet, positive and negative experiences have been demonstrated to represent two separate continuums at various levels of analysis including affective, motivational, behavioural, and cognitive (Clark, Watson, \& Mineka, 1994; MacLeo \& Byrne, 1996; MacLeod Byrne, \& Valentine, 1996). Theory suggests that human behaviors might be considered in terms of two systems: one that influences avoidance behavior, negative affect, and negative expectancies for the future, and the other that influences approach behavior, positive affect, and positive future expectancies (MacLeod et al., 1996). By acknowledging the distinction between positive and negative experiences, it becomes clear that we cannot assume an understanding of positive schemas through our knowledge of negative 
schemas. Thus, the importance of developing an understanding of the role positive schemas play in child psychopathology becomes increasingly evident.

Positive and negative systems have been found to exist on two continuums within cognitive domains. Research with both adults (e.g. MacLeod \& Byrne, 1996; MacLeod, Rose, \& Williams, 1993; MacLeod \& Salaminious, 2001) and youth (e.g., Muris \& Heiden, 2006) indicates that depression is often characterized by both the presence of negative cognitions as well as the absence of positive cognitions, while anxiety is more likely to be characterized by the presence of negative cognitions. For example, both anxious and depressed individuals have been found to show increased anticipation of negative future experiences, but only depression was characterized by reduced positive future expectations (MacLeod \& Byrne, 1996; MacLeod et al., 1993; MacLeod \& Salaminious, 2001; MacLeod, Tata, Kentish, \& Jacobsen, 1997; Muris \& Heiden, 2006). Thus, for anxious individuals, having negative future expectations does not exclude having positive future expectations.

At an even more fine-grained level of analysis, specific positive cognitions that have been found to play a central role in child resilience and psychopathology have also been found to exist on a separate continuum from their negative counterparts. Research indicates that the construct of optimism exists on a separate dimension from pessimism (e.g., Marshall, Wortman, Kusalas, Hervig, \& Vickers, 1992). Optimism has been linked to extraversion and positive affect, while pessimism is linked to neuroticism and negative affect. Similarly, trust and mistrust have been found to exist on two separate dimensions with people at times expressing both feelings within the same context (Lewicki, McAllister, \& Bies, 1998). Feelings of success and failure are also likely to exist on two 
dimensions, as obtaining success is not the same as avoiding failure (e.g, Hays, 1974). In line with these findings, it is logically consistent that possessing low levels of worthiness is not synonymous with having high levels of worthlessness. Having feelings of social connectedness does not exclude feeling socially isolated. Feeling low levels of control does not necessarily imply that one feels completely out of control.

Given that positive cognitions cannot likely be inferred from a lack of negative cognitions, it is important to focus on elucidating particular positive schemas that may play an important role in child psychopathology. The goal of the current study is to evaluate how specific positive schema themes relate to child psychopathology and resilience. Schema themes of interest were identified by surveying the literature and include: Worthiness, a sense that one has value and worth as a person; Self-efficacy, "beliefs in one's capabilities to mobilize the motivation, cognitive resources and courses of action needed to meet given situational demands" (Wood \& Bandura, 1989); Optimism, one's belief that outcome expectancies will be favorable, or good rather than bad (Scheier \& Carver, 1985); Success/Competence, the tendency to anticipate that one's performance will typically be followed by success; Trust, a feeling that one can rely on others and "accept vulnerability based upon positive expectations of the intentions or behaviors of another" (Rousseau, Sitkin, Burt, \& Camerer, 1998); and Social Connectedness, a sense of closeness to others including family, friends, and social groups, that enables a person to feel a sense of belongingness (Lee \& Robins, 1995).

The current study examines how each of these schema themes differentially relates to depression, anxiety, and resilience. Furthermore, to confirm that positive cognition is not the inverse of negative cognition, the current study will evaluate the 
unique contribution positive schemas play in predicting various developmental outcomes in adolescence, over and above that explained by negative schemas.

\section{Positive Schema Questionnaire}

No single measure currently exists to examine particular positive schema themes' relation to psychopathology and well-being in early adolescence. Indeed, the almost exclusive focus of cognitive theories of child psychopathology on negative rather than positive cognitive schemas (e.g., Abela \& Hankin, 2008) is reflected in previous attempts to develop schema inventories for children (Stallard \& Rayner, 2005). Based on Young's (1999; Young et al., 2003) Schema Theory, there have been some attempts to develop an inventory to evaluate children's negative schemas (e.g., Schema Questionnaire for Children; Stallard \& Rayner, 2005); however, existing inventories fail to adequately reflect the complexity of the schemas assessed, and more importantly no inventory has attempted to evaluate children's positive schema content.

Young $(1990 ; 1991 ; 1994)$ initially developed the Young Schema Questionnaire (YSQ), a measure used to assess the presence of early maladaptive schemas (EMS) in adults, and later Young (1994) developed a short version of the questionnaire (YSQ-S). The YSQ and the YSQ-S have been used extensively in research with adolescents and adults (e.g., Lumley \& Harkness, 2007; Muris, 2006; Simmons, Cooper, Drinkwater, \& Stewart, 2006); however, given the lengthy and complex nature of the YSQ-S, other attempts have been made to develop a more effective schema assessment tool for children. Stallard and Rayner (2005) developed the Schema Questionnaire for Children (SQC), which involves a single item for each EMS. Still, the complexity of the various 
dimensions of the schemas are not adequately assessed using a single-item for each schema, and this measure solely focuses on evaluating negative childhood schemas.

Given the importance of a proper tool for evaluating schemas in furthering research in this area, the current study aims to construct a developmentally sensitive Positive Schema Questionnaire to evaluate the presence of positive core schemas in adolescence. This new measure will assess adaptive schema themes including Worthiness, Self-Efficacy, Optimism, Success, Interpersonal Trust, and Connectedness.

\section{Positive Schemas and Depression}

Research indicates that cognitive models of child depression ought to be adapted to incorporate positive cognitions (e.g., McClain \& Abramson, 1995), as it is not just the presence of negative schemas that creates vulnerability to depression, but the dearth of positive schemas may also function as a cognitive vulnerability factor. While there appears to be convincing evidence that low levels of positive schemas are implicated in childhood depression (e.g., Jaenicke et al., 1987; Prieto et al., 1992; Shirk et al., 1998; Whitman \& Leitenberg, 1990), the majority of research evaluates positive schemas on a broad level in which positive states are assessed across all situations and all content domains (Dykman, Abramson, Alloy, \& Hartlage, 1989). Evaluating specific cognitive schemas is very important, as information is encoded in a manner depending on the match between the information provided and the schemas possessed by the individual. Thus, to gain a more comprehensive picture of the role of positive schemas in depression, it is essential to look at specific schema content areas.

The majority of research on positive schemas and child depression focuses on global positive schemas. Emphasizing the importance of studying positive schemas in 
child psychopathology, some research indicates that lacking positive global self-schemas may play an even more important role than negative schemas in the diathesis for depression in children (e.g., McClain \& Abramson, 1995; Whitman \& Leitenberg, 1990). For example, Whitman and Leitenberg conducted a study on children in grades 4 and 5 , comparing those with self-reported symptoms of depression to non-depressed children. After completing a word association task the subjects were given feedback regarding their correct and incorrect responses. Depressed and control subjects did not differ in their recall of incorrect answers; however, depressed subjects were much less accurate in their recall of correctly answered words. This indicated that children who experience depression have problems processing positive, but not negative information. Consistently, McClain and Abramson (1995) found that non-depressed, mildly depressed, and severely depressed students could only be differentiated based on their levels of positive schemas and not based on their negative schemas. As schemas became less positive, the severity of depression increased, supporting the idea that lacking sufficiently positive schemas might act as the vulnerability factor in Beck's model. Further emphasizing the importance of positive schemas in vulnerability to depression, Prieto et al. (1992) found that depressed individuals possessed less positive schemas than non-depressed individuals, but still identified more positive than negative schemas overall.

While it is evident that low levels of positive schemas play an important role in vulnerability to depression, very little is known about the specific schema themes that serve as a diathesis to childhood depression. This is a very important area of research, as according to cognitive content hypothesis, the specific cognitive schema theme possessed by an individual will play an important role in determining pathological outcomes (Beck, 
1967; Young, 1999; Young et al., 2003). Furthermore, research indicates that depression is related to feedback in a wide variety of domains, with some domain feedback more strongly related to depression than others (Cole, 1991). While very little research has evaluated the role of individual schema themes in depression, there is clear evidence that depression is related to various positive cognitive constructs across a wide variety of domains.

Feelings of worthiness, have been found to be strongly implicated in child (e.g., Cole, Martin, Peeke, Seroczynski, \& Fier, 1999; Garber \& Hilsman, 1992; Garber, Robinson, \& Valentiner, 1997) and adult depression (e.g., Brockner \& Guare, 1983; Tennen, \& Herzberger, 1987). In a study by Cole, Jacquez, Truss, Pineda, Weitauf et al. (2009), a measure of a child's global self-worth was found to be one of the cognitive constructs most highly associated with depressive symptoms. Furthermore, Garber and Hilsman found that low self-worth was not a result of the participants' current mood, and thus not just a symptom of depression, but rather a marker of cognitive vulnerability to depression. Thus, the schema theme of worthiness may be important to explore when considering vulnerability to depression.

Optimism may also be an important schema theme for predicting depression. Optimism has been found to be inversely related to depressive symptoms in several adult (Achat, Kawachi, Spiro, DeMolles \& Sparrow, 2000; Andersson, 1996; Carver \& Gaines, 1987; Marshall \& Lang, 1990) and youth populations (Chang, 1996; Puskar, Sereika, Lamb, Tusaie-Mumford, \& Mcguinness, 1999). Research indicates that adolescents who are more optimistic tend to engage in more effective coping strategies, while those who are less optimistic tend to be more avoidant in their coping strategies (Chang, 1996; 
Puskar et al., 1999). Thus, optimism may be an important theme to explore for predicting depression vulnerability.

Self-efficacy, or a person's belief in his/her ability to control outcomes has also been found to play a role in determining the level of depression a person experiences in the face of threat (Bandura, 1991, 1993; Bandura, Pastorelli, Barbaranelli, \& Caprara, 1999; Marshall \& Lang, 1990). In child populations, research indicates that self-efficacy is implicated in depression both directly, as well as indirectly through the impact it has on social and academic achievement (Bandura et al., 1999). Thus, the schema theme of selfefficacy may be implicated in depression vulnerability.

In a related field of study, research on various forms of success have been significantly correlated with depression symptoms in youth (e.g., Blechman, McEnroe, Carella, \& Audette, 1986; Cole, Martin, Peeke, Serocynski, \& Fier, 1999; Cole, Martin, Peeke, Serocynski, \& Hoffman, 1998; Feshbach \& Feshbach, 1987; Lefkowitz \& Tesiny, 1980). Depression has been found to be negatively related to child self perceived competence in several domains including: social, academic, conduct, physical attractiveness, and sports and this theme may be important to explore for predicting depression vulnerability (e.g., Cole, 1991; Cole et al., 1999; Cole et al., 1998).

Finally, social connectedness has also been found to be negatively associated with levels of depression in children (e.g. Bell-Dolan, Reaven, \& Peterson, 1993; Fauber, Forehand, Long, Burke, \& Fuast, 1987; Rubin, Chen, McDougall, Bowker, \& McKinnon, 1995; Williams \& Galliher, 2006) and college students (Armstrong \& Oomen-Early, 2009; Lee, Draper, \& Lee, 2001; Williams \& Galliher, 2006). Similarly, negative relations have been found between interpersonal trust and depression in youth (Lester \& 
Gatto, 1990) and undergraduate samples (Benhua \& Yanxiang, 2004).

While negative relations have been consistently found between various positive constructs and depression, no research has investigated links between specific schema themes and depression in children or evaluated the unique role of each of these schema themes in predicting depressive symptoms. Given the consistent theme of an inverse relationship between various positive cognitive themes and depression, I hypothesized that a negative relationship will exist between a child's overall positive schemas as well as each individual schema theme and depression symptoms. However, given that each positive schema plays a specific role in creating vulnerability to depression, when the covariance between schemas is accounted for, particular schema themes were hypothesized to be more central to understanding vulnerability to depression. Consistent with Beck's content specificity hypotheses which theorizes that the cognitive content implicated in depression reflects themes of negative self-views, hopelessness, and pessimism (Clark, Beck, \& Brown, 1989; Clark, Beck \& Stewart, 1990), I hypothesized that the schemas of worthiness and optimism would be the strongest predictors of depressive outcomes in children.

\section{Positive Schemas and Anxiety}

While the role of positive cognition in anxiety disorders has also been neglected in favor of a focus on negative cognitions, recent literature indicates that an understanding of positive schemas would considerably strengthen our understanding of anxiety disorders (Casey, Oei, \& Newcombe, 2004; Muris, 2002). A large body of evidence indicates that negative systems are related to anxiety while positive systems are not (e.g., Clark \& Watson, 1991; MacLeod \& Byrne, 1996; MacLeod et al., 1997). For 
example, research comparing anxiety and depression often indicates that depression is associated with both high negative and low positive experience, while anxiety is only associated with negative, in behavioural (e.g., Clark et al., 1994) affective (e.g., Clark \& Watson, 1991) and cognitive systems (e.g., MacLeod \& Byrne, 1996; MacLeod \& Salaminious, 2001; MacLeod et al., 1997; Muris \& Heiden, 2006). Contradicting these findings, literature on specific themes of positive cognition indicates that low positive schemas may also serve to create vulnerability to anxiety (e.g., Bogels \& Zigterman, 2000; Casey, Oei, Newcombe, \& Kenardy, 2004; Matsuo \& Arai, 1998; Muris, 2002; Schmidt, Trakowski, \& Staab, 1997; Stoler \& McNally, 1991; Yue, 1996). Previous conclusions that no relation exists between positive cognition and anxiety may be a result of looking at global positive cognition, rather than looking at the relations that exist between specific positive schemas and anxiety. Looking at the global relationship between positive schemas and anxiety may mask more complex relationships that exist at the individual schema level.

While the majority of theories proposed to explain vulnerability to anxiety focus on negative cognitions (e.g. Clark, 1993), there is evidence that some positive schema themes are negatively associated with anxiety (e.g., Casey et al., 2004; Schmidt et al., 1997; Stoler \& McNally, 1991). Beck et al. (1985) propose that vulnerability to anxiety is a result of both negative schemas surrounding danger combined with a lack of positive schemas regarding control over danger. Consistently, Bandura (1988) argues that one's self-efficacy regarding coping ability plays a role in determining one's perception of danger. Thus, vulnerability to anxiety is determined based on both negative cognitions surrounding danger and positive cognitions surrounding self-efficacy. Similarly, in 
attempt to explain the range of responses to actual threatening situations, Rachman (1990) proposed that self-confidence surrounding coping is what distinguishes those who respond effectively from those who respond with anxiety to dangerous situations.

Literature supports the idea that low levels of positive cognitions regarding control and coping self-efficacy play a role in vulnerability to anxiety disorders in both adult (e.g., Casey et al., 2004; Schmidt et al., 1997; Stoler \& McNally, 1991) and youth populations (e.g., Bogels \& Zigterman, 2000; Matsuo \& Arai, 1998; Muris, 2002; Yue, 1996). Adult patients with agoraphobia and panic disorder have been found to exhibit low levels of panic self-efficacy (Casey et al., 2002; Telch, Brouillard, Telch, Agras, \& Taylor, 1989), and those lacking strong beliefs in their ability to cope with anxiety have been found to be at greater risk for panic attacks (Schmidt et al, 1997). Self-efficacy regarding coping and control was also found to play a large role in determining the severity of panic disorder (Casey et al., 2004; Clum, Watkins, Borden, Broyles, \& Hayes, 1993; Cote, Gauthier, Laberge, \& Cormier, 1994; Lidren, Watkins, Gould, Clum, Asterino, \& Tulloch, 1994; Williams \& Falbo, 1996; Williams \& Zane, 1989). Furthermore, in an evaluation of post-treatment effectiveness for an agoraphobia intervention, in the presence of a cognitive bias, coping ability distinguished recovered patients from those who were unrecovered (Stoler \& McNally, 1991). Consistently, low self-efficacy regarding one's ability to cope with danger was found to be implicated in various childhood anxiety disorders including social phobia, separation anxiety disorder, and generalized anxiety disorder (e.g., Bogels \& Zigterman, 2000; Matsuo \& Arai, 1998; Muris, 2002; Yue, 1996).

An important gap in the research literature currently exists regarding links between 
self-efficacy schemas and anxiety disorders for children. Furthermore, an understanding of the role of other positive schema themes such as worthiness, optimism, success, trust, and social connectedness in anxiety is unclear. No convincing evidence exists that implicates other positive schema themes in childhood anxiety. While social connectedness has been found to be negatively associated with trait anxiety, research indicates that a relationship may not exist between connectedness and state anxiety (Lee \& Robins, 1998). Thus, schemas of social connectedness may not play an important role in determining one's immediate feelings of anxiety. Additionally, while some research indicates that self-esteem may buffer anxiety symptoms (e.g., Greeenberg, Pyszczynski, Solomon, Pinel, Simon \& Jordan, 1993; Many \& Many, 1975), other research indicates that when controlling for other domains of positive cognition such as social connectedness, self-esteem may not predict a large portion of variance in anxiety $(2 \%$; Lee \& Robins, 1998). While optimism has been found to be inversely associated with anxiety in populations including children (e.g., Dewberry \& Richardson, 1990; Neverlien \& Johnsen, 1991; Smith, Pope, Rhodewalt, \& Poulton 1989), the association between optimism and anxiety has been explained by the influence of optimism on developing stronger coping self-efficacy (Scheier \& Carver, 1985, 1992; Smith et al., 1989; Solberg \& Segerstrom, 2006). Consistently, researchers have found the covariance between selfefficacy and optimism may actually account for the relationship between optimism and other affective disorders (Marshall \& Lang, 1990).

Given that research suggests that positive cognition is unrelated to anxiety (e.g., Clark \& Watson, 1991; MacLeod \& Byrne, 1996; MacLeod et al., 1997; Treadwell \& Kendall, 1996), and equally persuasive evidence that positive cognitions of control and 
coping self-efficacy are negatively related to anxiety (e.g., Bogels \& Zigterman, 2000;

Casey et al, 2004; Matsuo \& Arai, 1998; Muris, 2002; Schmidt et al., 1997; Stoler \& McNally, 1991; Yue, 1996), it is important to expand our understanding of the relation between anxiety and particular positive schema themes. Thus, I hypothesized that no global relationship would exist between positive schemas and anxiety; however, anxiety would be inversely related to self-efficacy, while other constructs of interest such as worthiness, optimism, success, trust, and social connectedness would be unrelated to anxiety.

\section{Positive Schemas and Resilience}

While research has investigated how the absence of positive schemas impacts child development (e.g., Jaenicke, et al., 1987; Prieto et al., 1992; Shirk et al., 1998), little research has evaluated how the presence of positive schemas impacts development. More specifically, no research explicitly investigates links between the presence of positive schemas of various themes and resilience, or one's ability to adaptively cope with adversity (Wagnild \& Young, 1993). However, research on positive emotions and affect, as well as on positive cognition, supports the idea that positive states not only mark mental health, but actually facilitate future resilience (e.g., Diener \& Diener, 1996; Fredrickson, 2004; Fredrickson \& Joiner, 2002). This research is consistent with the idea that positive schemas are likely to increase childhood resilience.

Research on positive emotions and affect indicates that positive states do not only signal positive functioning, but also play a role in producing future positive states and resilience (Fredrickson, 2004). In the broaden-and-build theory of emotions, Fredrickson argues that positive states "broaden" a person's thoughts and actions, and thus promotes 
approach behaviours and engagement and exploration of the environment, which in turn builds a person's personal resources for successful coping. This hypothesis has been supported through research which indicates that these positive states create an "upward spiral" in which positive emotions and broadened thinking aid in finding positive meaning in situations, which in turn facilitates more positive coping and higher resilience (e.g., Fredrickson \& Joiner 2002). Consistently, research supports the idea that people are able to cope with adversity by finding positive meaning in their daily experiences and within adversity (E.g. Affleck \& Tennen 1996; Folkman \& Moskowitz, 2000; Fredrickson 2000).

Similarly, research on positive cognition indicates that positive cognitions are not only necessary for mental health and happiness, but might even be necessary to maintain a neutral emotional state (Cacioppo, Gardner, \& Berntson, 1999; Diener and Diener 1996). While many theorists argue that accurate perception is essential for mental health (e.g., Colvin \& Block, 1994; Colvin, Block, \& Funder, 1995), there is also evidence indicating that positively biased self-perceptions are adaptive and "normal" (Taylor \& Brown, 1988, 1994). Mental health may only exist in the presence of a positive cognitive bias, as having a positive bias allows information to be filtered in a positive direction, creating protection when exposed to negative information (e.g., Taylor \& Brown, 1988, 1994). Research has consistently found that the majority of people have positively biased self-views (e.g., Greenwald, 1980; Taylor \& Brown, 1988), exaggerated beliefs regarding personal control (e.g., Fleming \& Darley, 1986; Miller \& Ross, 1975) and unrealistic optimism (Langer \& Roth, 1975). In fact, lacking these biases has been linked to negative mental health (e.g., Abramson \& Alloy, 1981; Coyne \& Gotlieb, 1983; Golin, Terrell, \& 
Johnson, 1977; Golin, Terrell, Weitz, \& Drost, 1979; Ruehlman, West \& Pasahow, 1985; Watson \& Clark, 1984).

Given the evidence that positive states and cognitions are positively linked to mental health likely by influencing people to filter information in a positive manner, I hypothesized a strong positive correlation between global positive schemas and resilience. Additionally, I planned to explore multivariate relations of particular positive schema themes to resilience to identify their relative strength.

Summary of Hypotheses

The goal of the current study is to gain an understanding of the role of positive schemas of Worthiness, Self-Efficacy, Optimism, Success, Interpersonal Trust, and Social Connectedness in child depression, anxiety, and resilience. As an initial step in developing a more comprehensive understanding of the role of positive schemas in development, the first goal of the current study was to develop a psychometrically sound Positive Schema Questionnaire for children. Using the newly developed PSQ, it was hypothesized that a global measure of positive schemas would be negatively associated with depression, unrelated to anxiety, and positively related to resilience in children. Positive schemas were hypothesized to predict unique variance in depression and resilience scores, over and above that explained by negative schemas. Furthermore, given the unique role of each schema theme of interest, it was hypothesized that when the covariance between the various schemas was accounted for, particular schema themes would predict unique variance in each construct of interest. 
Method

\section{Participants}

Participants were 172 adolescent boys $(n=84)$ and girls $(n=88)$, age 9 to $14(M=$ $11.44, S D=1.17)$, in grades 5 to 8 . Participants were $77 \%$ Caucasian $(n=130)$, and the other $23 \%$ of the participants ( $n=39)$ were from ethnically diverse backgrounds including Asian, African American, Hispanic/Latino, First Nations, and "Other." The students were recruited from four elementary schools from the Wellington Catholic District School Board in Guelph, Ontario.

Measures

Positive Schema Questionnaire (PSQ). This 36-item, 6-point Likert self-report questionnaire is a measure of positive core schema themes in children. Participants rate how much they agree with statements such as "I look at the bright side of things;" and "I believe in myself." Schema domains assessed include: (a) Worthiness (b) Self-Efficacy (c) Optimism (d) Success (e) Trust, and (f) Social Connectedness.

Schema themes were selected by surveying literature related to emotional resilience and identifying constructs frequently found to play a role in vulnerability to child psychopathology. After surveying the literature, schema definitions were obtained for each schema theme, and items for each domain were generated by a group of graduate and undergraduate researchers. Clinical psychologists and graduate students selected items that best represented the central features of each schema and these items were administered to 172 children aged 9-14. A Factor Analysis was conducted to validate the factor structure of the scale. Following factor analysis, the internal consistency for the scale was .93 . 
Schema Questionnaire for Children (SQC: Stallard \& Rayner, 2005). The SQC is a 15-item, 6-point ${ }^{1}$ Likert self-report measure of children's negative core schemas. Each of the items in the scale represents a single Early Maladaptive Schema theme proposed by Young (1990). Psychometric support has been examined and the scale has been found to possess adequate face validity, as well as convergent validity for 12 of the $15 \mathrm{SQC}$ items when comparing this measure to the Young Schema Questionnaire (Stallard \& Rayner). The internal consistency estimate for the SQC in the current sample was .73. Multidimensional Anxiety Scale for Children-10 (MASC-10; March, 1997). The MASC is a 10-item, 4-point likert self-report measure of children's anxiety. This measure is a shortened version of the Multidimensional Anxiety Scale for Children, and is a unidimensional measure that combines the four anxiety scales, including Physical Symptoms, Social Anxiety, Harm Avoidance, and Separation/Panic items. This measure is a useful screening tool and can be used effectively within group settings. Psychometric support has been found for this measure and it has been found to possess good test-retest reliability (March, Sullivan, \& Parker, 1999). The internal consistency estimate for the MASQ-10 in the current sample was .74.

Children's Depression inventory (CDI; Kovacs, 1981). The CDI is a 27-item, 3point Likert self-report questionnaire used to assess children's behavioural, affective and cognitive symptoms of depression. Children are shown statements related to their moods and asked to pick out sentences that best describe them (e.g. "I'm sad once in a while; I am sad many times; I am sad all the time"). This measure has high internal-consistency and test-retest reliability, as well as strong convergent and predictive validity (Carey,

\footnotetext{
${ }^{1}$ A 6-point likert scale was used instead of a 5-point scale to be consistent with the PSQ
} 
Faulstich, Gresham, Ruggierio, \& Enyart, 1987). The internal consistency estimate for the CDI in the current sample was .85 .

Resilience Scale (RS; Wagnild \& Young, 1993). The RS is a 25-item, 7-point Likert questionnaire used to measure beliefs about one's ability to successfully cope with adversity. Respondents rate how strongly they agree with statements related to resilience (e.g., "I can be on my own if I have to"; "I usually take things in stride"). The scale assesses two domains of resilience including (1) personal competence, and (2) acceptance of self and life. Higher scores on the scale indicate higher levels of resilience.

Psychometric support has been found for the internal consistency, reliability, and concurrent validity of the scale (Wagnild \& Young). This measure was also found to have strong internal consistency within the current sample .93 .

\section{Procedure}

The current study was introduced to the participants by undergraduate research assistants who visited the participating classrooms in the schools involved in the study. The students were provided with details about the study and encouraged to take an information package and consent form home to their parents for permission to participate. Of the 965 students who were provided with information packages, 269 agreed to participate in the study. The sample decreased to 172 due to absences, missing data, and withdrawal of consent from the youth. Missing data was replaced by mean values when less than $15 \%$ of the data was missing.

Data collections took place within an assigned area of each of the four participating schools (e.g., gymnasium, library, technology room). The rooms were set up with 25 Acer Aspire netbook computers. Participants were each seated at their own 
desk/table and chair, and each person was provided with his/her own computer, mouse, and privacy shield. At the beginning of each data collection the students were provided with verbal and written information about the study, and were given an opportunity to consent to the study. Following instructions, the participants completed several selfreport questionnaires, which were programmed onto the computers. The laptop program led participants through each step of the procedure, and instructions were provided for the students in writing. Additionally, a minimum of five research assistants were present at each data collection, to provide instructions and answer individual questions.

The PSQ was completed first, followed by the SQC, MASC-10, CDI, and lastly the RS. The procedure took approximately 1 hour to complete. Following participation the youth were thanked and given a snack or toy for participating. Parents of children who reported clinically concerning levels of depression or anxiety were contacted and provided with relevant mental health information or contacts.

Results

The Development of the Positive Schema Questionnaire

An Exploratory Factor Analysis (EFA) was conducted to evaluate the Positive Schema Questionnaire's underlying factor structure and to confirm its usefulness as a measure for assessing child positive schemas. Principal axis factoring (PAF) was selected to assess the latent factor structure of the measure, consistent with past schema measure development (e.g., Cecero, Nelson, and Gillie, 2004). Orthogonal varimax rotation technique was selected, as this technique is most frequently used in measure development, and has been found to yield more accurate estimates than the oblique rotation (Gerbing \& Hamilton, 1996). 
Several techniques were used to decide on the number of factors to retain in the analysis including eigenvalue $>1.00$ and scree tests. Additionally, given the subjectivity in determining the cut-off point for the scree test, an examination of the interpretability of alternative factor solutions was conducted with different numbers of factor solutions (Costello \& Osborne, 2005; Floyd \& Widaman, 1995). As recommended by Costello and Osborne, multiple factor analyses were conducted setting the number of factors manually, at the projected number based on the a priori factor structure, at the number of factors determined by the scree test, and at factor solutions above and below those numbers. The item loadings were compared for the various factor solutions, and the factor with the cleanest structure was considered to be the best fit for the data. Criterion for the best fit involved: the most item loadings above .40 , the fewest number of crossloadings, and with a minimum of three items representing a common factor.

Given that the a priori factor structure predicted 6 factors, eigenvalues $>1$ yielded 6 factors, and the scree plot yielded approximately 2 factors, factor analyses were conducted extracting $2,3,4,5$, and 6 factors to determine the solution that best fit the data. According the aforementioned criteria, the results of these analyses indicated that a 5 -factor solution most strongly represented the data, and accounted for $56.93 \%$ of the total variance.

In order to achieve simple structure, items loading on more than one factor above .40 , and those not loading on any factor above .40 , were discarded. This resulted in the dropping of 15 of 36 items. Items with communalities lower than .40 were also removed in order to eliminate variables that do not have much of their variance accounted for by the factor solution (Costello \& Osborne, 2005; Ford, MacCallum, \& Tait, 1986). This 
resulted in the dropping of 1 more item for a total of 20 items in the final solution. This process resulted in a 5 -factor solution that accounted for $62 \%$ of the total variance. The resultant higher-order factor solution was generally consistent with the a priori categories and yielded five factors including: Self-Efficacy, Success, Interpersonal Trust, Optimism, and Worthiness (See Table 1).

\section{Descriptive Characteristics}

Means and standard deviations for all study variables for the total sample, males, females, Caucasian and diverse ethnicity participants are presented in Table 2.

Schemas. Positive schema scores assessed by the Positive Schema Questionnaire ranged from $34-119$. Positive schema total scores did not relate to sex, $t(168)=.04, p=$ .10 , age, $r=.04, p=.60$, or ethnicity, $t(50)=1.04, p=.31^{1}$. Descriptive statistics were also evaluated for individual positive schema themes. Self-Efficacy scores ranged from $6-24$ and did not relate to sex, $t(168)=.22, p=.83$, age, $r=.015, p=.85$, or ethnicity, $t(49)=$ $1.44, p=.16^{1}$. Success scores ranged from $4-6$, and did not significantly relate to sex, $t(168)=-.07, p=.94$, age, $r=.14, p=.08$, or ethnicity, $t(167)=.54, p=.59$. Trust scores ranged from $6-24$, and were not related to sex, $t(168)=-1.32, p=.19$, age, $r=.02, p=$ .83 , or ethnicity, $t(52)=1.31, p=.20^{1}$. Optimism scores ranged from $4-24$ and did not relate to sex, $t(168)=-.20, p=.85$, age, $r=.02, p=.84$, or ethnicity, $t(167)=.10, p=$ 93. Lastly, Worthiness scores ranged from $6-2$, and did not relate to sex, $t(168)=1.63$, $p=.11$ age, $r=-.01, p=.89$ or ethnicity, $t(167)=1.01, p=.31$.

\footnotetext{
${ }^{1}$ Equal variances not assumed
} 


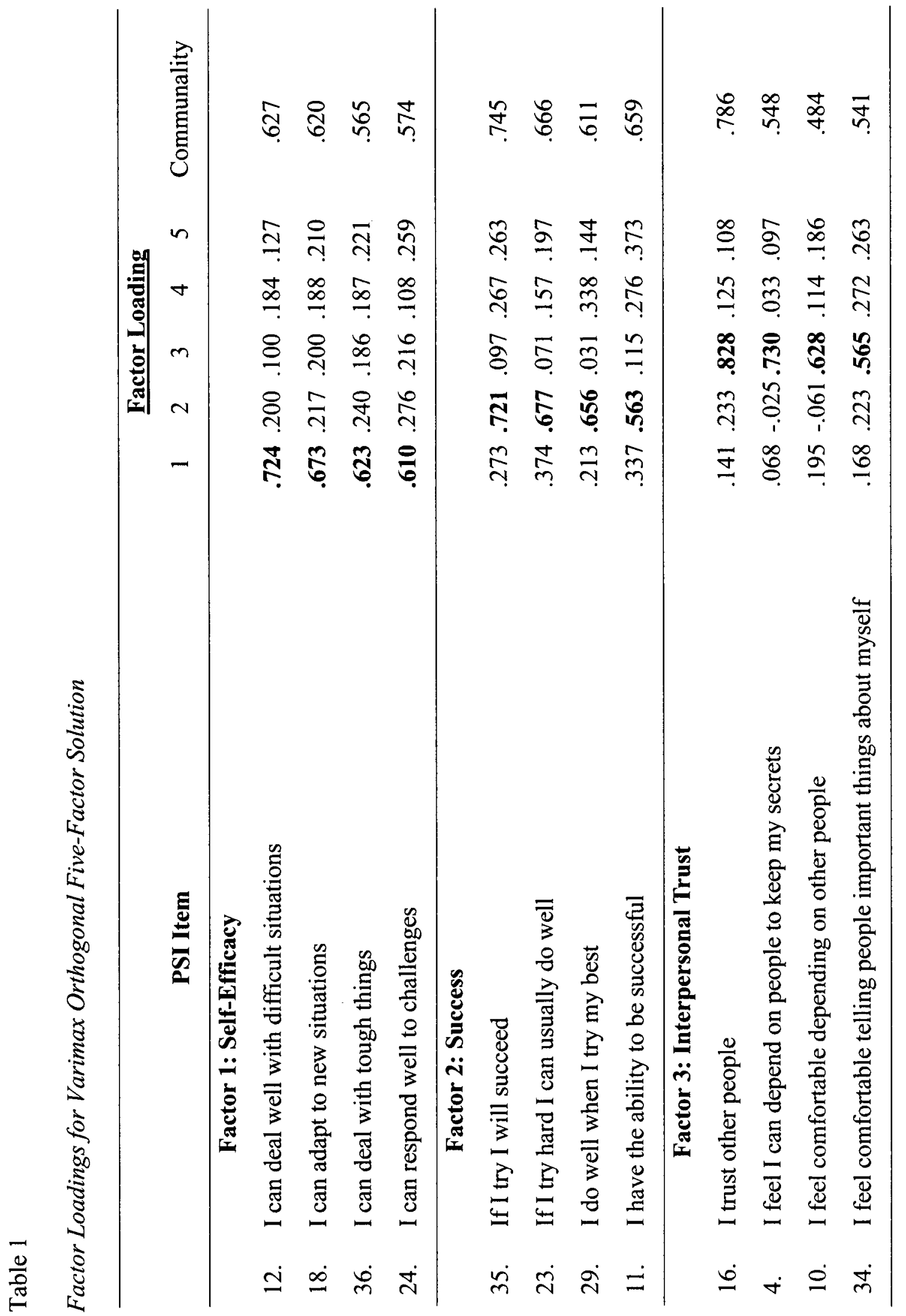




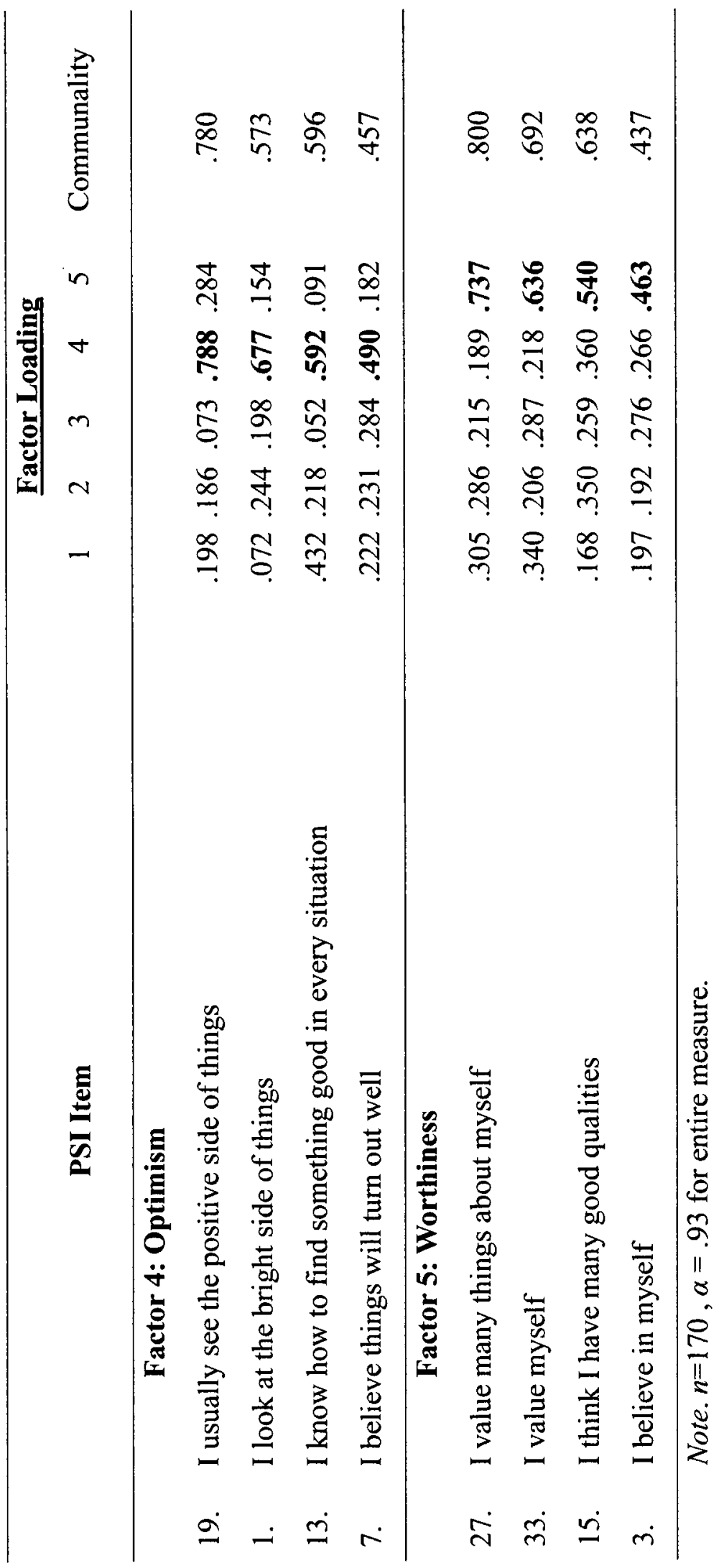




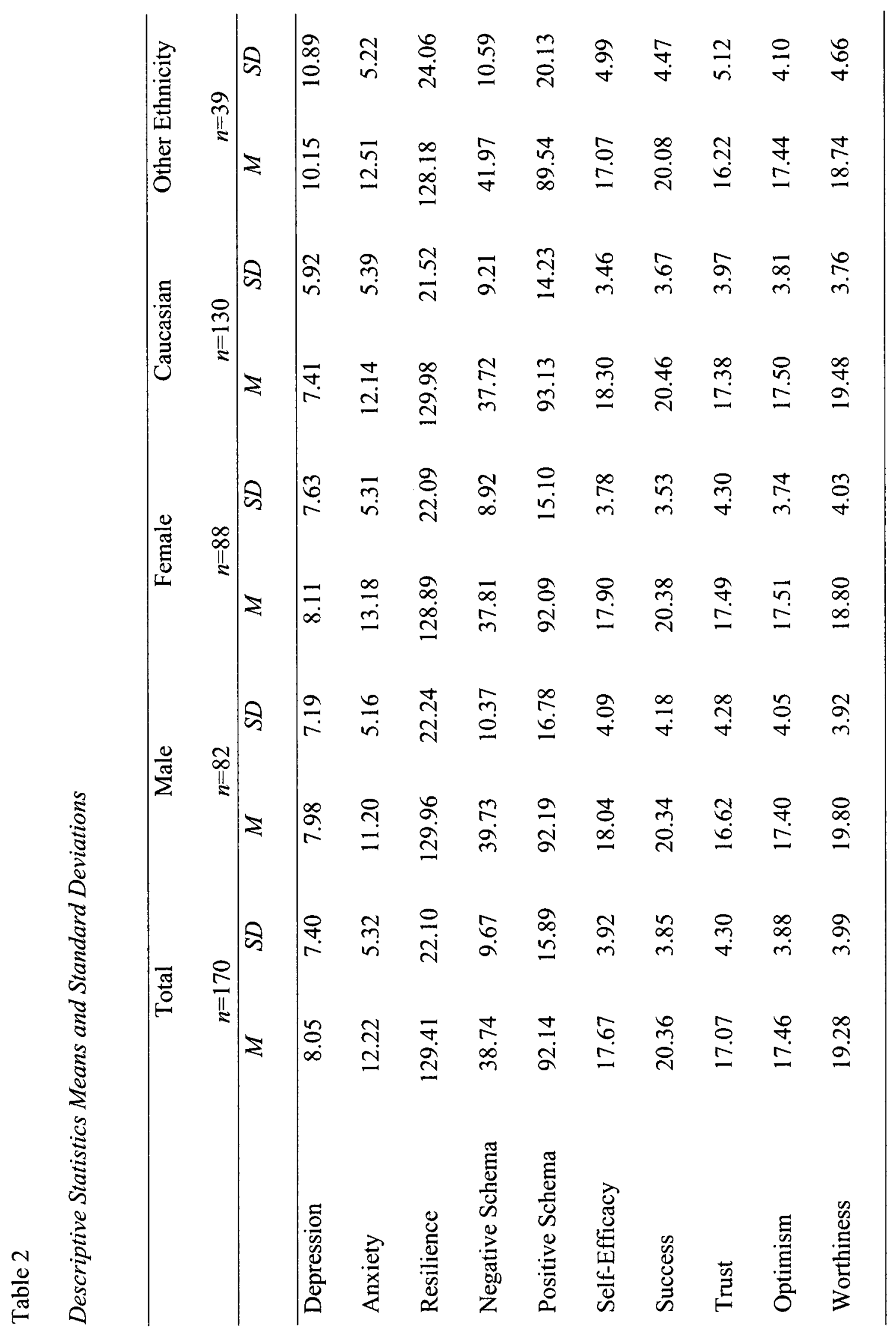


Negative schema scores assessed with the SQC, ranged from $20-70$. Negative schemas were not significantly related to sex, $t(168)=1.63, p=.11$, or age, $r=0.09, p=$ .26; however, negative schemas were significantly related to ethnicity, with ethnically diverse participants reporting higher negative schema total scores than Caucasian participants, $t(167)=-2.44, p=.02$. Given the significant relationship between negative schemas and ethnicity, ethnicity will be included in models of risk and resilience reported below.

Depression symptoms. Depression symptom scores assessed by the CDI ranged from $0-41$, with $8.5 \%$ of the sample falling in a clinically elevated range according to criteria set by Kovacs (1981). Depression scores did not relate to sex, $t(168)=-.12, p=$ .90 , age $r=.12, p=.14$, or ethnicity, $t(45)=-1.51, p=.14^{1}$.

Anxiety symptoms. Anxiety symptom scores assessed by the MASQ-10 ranged from $1-26$, with $16.4 \%$ of the sample falling in a clinically elevated range with criteria set by March (1997). Anxiety scores did not relate to age, $r=-.12, p=.11$, or ethnicity, $t(167)=-.38, p=.70 ;$ however, anxiety did relate significantly to sex, with girls expressing significantly more anxiety than boys, $t(168)=-2.47, p=.01$. Given the significant relationship between anxiety and sex, sex will be included in models reported below, to account for the variance explained by this relationship.

Child resilience. Child resilience scores measured using the Resilience Scale, ranged from 34 to 119 . Resilience was not related to sex, $t(168)=.32$, age, $r=.11, p=$ $.15, p=.75$, or ethnicity, $t(167)=.45, p=.66$.

${ }^{1}$ Equal variances not assumed 


\section{Positive Schemas and Depression}

The relation between positive schemas and depression. To evaluate the hypothesis that global positive schemas would be negatively related to child depression symptoms, a Pearson correlation analysis was conducted (see Table 3). Consistent with hypotheses, a significant negative correlation was found between depression scores and global positive schemas. Furthermore, Pearson correlation analyses were conducted to evaluate the association between individual schema themes and depression. Significant negative correlations were found between depression and all positive schema themes including Self-Efficacy, Success, Trust, Optimism, and Worthiness.

Unique contribution of positive schemas for predicting depression. A hierarchical linear regression analysis was computed to determine whether positive schemas explain additional significant variance in depression, beyond that explained by negative schemas (see Table 4). The predictor variables were entered in three blocks: (1) ethnicity, (2) negative schema total, and (3) positive schema total. The first background variable entered into the regression, ethnicity, resulted in a statistically significant increase in explained variance in depression, $\Delta R^{2}=.06, F(1,166)=9.83, p<.01$. In the second step of the regression, negative schemas accounted for a statistically significant increase in explained variance, and accounted for $21 \%$ of variance in depression scores, $\Delta R^{2}=.21$, $F(1,165)=47.45, p<.001$. Consistent with hypotheses, in the third step of the regression, positive schemas accounted for a statistically significant increase in the variance of depression symptoms, $\Delta R^{2}=.27, F(1,165)=95.10, p<.001$, indicating that positive schemas predict additional variance beyond that accounted for by negative schemas alone. 


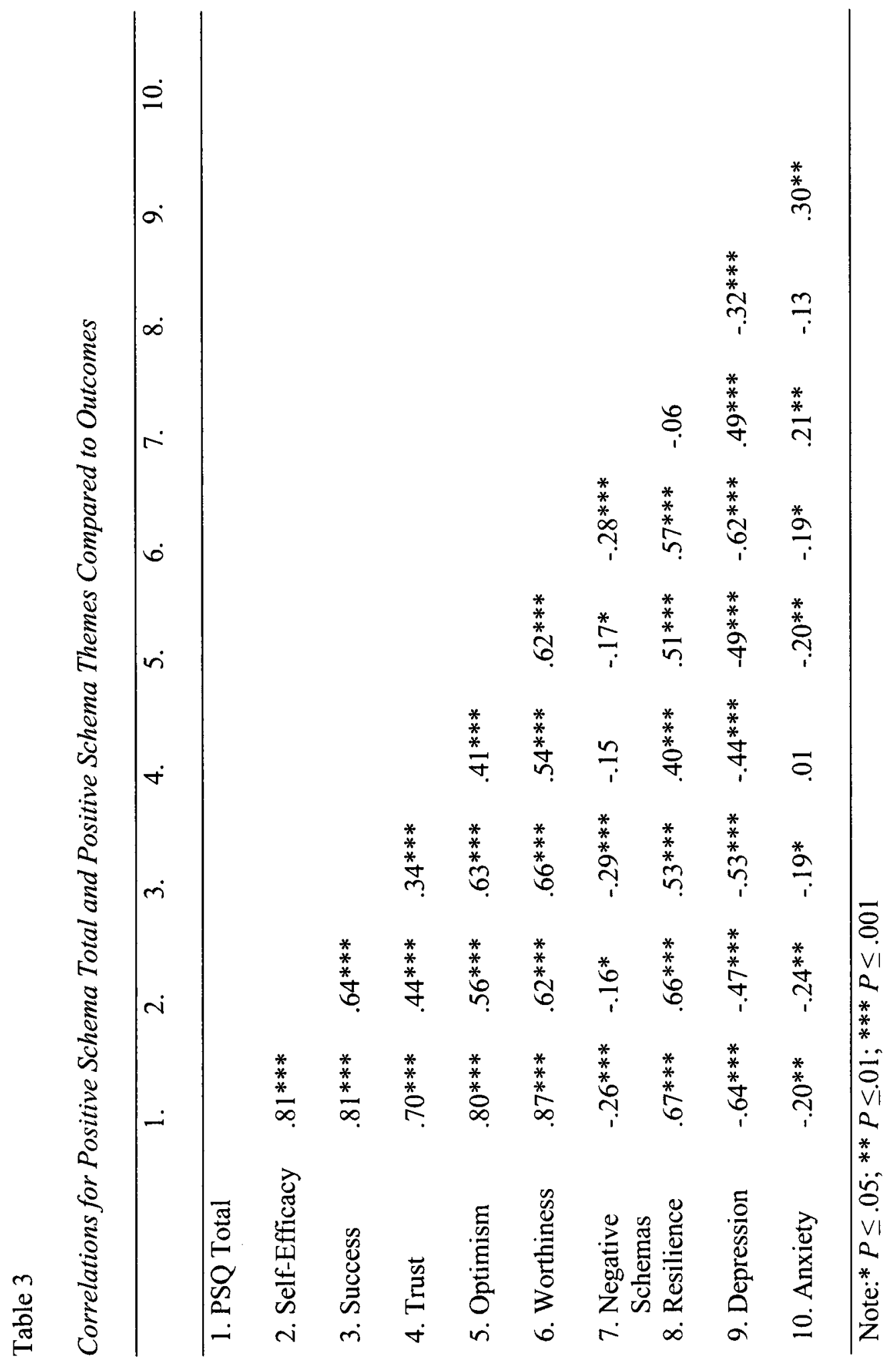




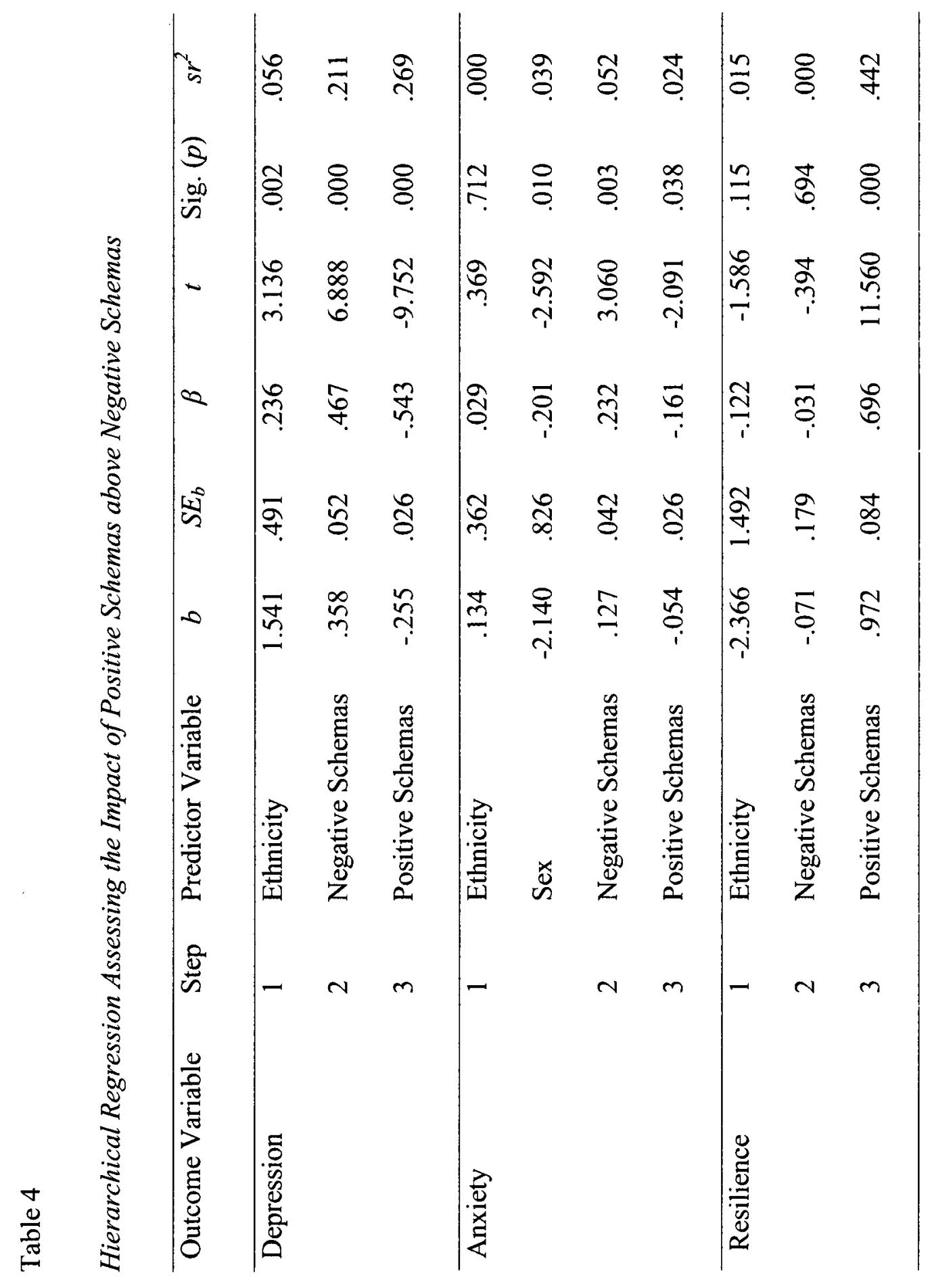


The contribution of individual schema themes for predicting depression. A hierarchical linear regression analysis was computed to evaluate the hypothesis that specific schema themes would emerge as particularly relevant to the development of depression in adolescents (see Table 5). The data were entered in three blocks: (1) ethnicity, (2) negative schema total, and (3) Self-Efficacy, Success, Trust, Optimism, and Worthiness. In the first step of the regression, ethnicity, resulted in a statistically significant increase in explained variance in depression, $\Delta R^{2}=.06, F(1,166)=9.83, p$ $<.01$. In the second step of the regression, negative schemas accounted for a statistically significant increase in explained variance, $\Delta R^{2}=.21, F(1,165)=47.45, p<.001$. The third block of this regression analysis also accounted for a statistically significant increase in explained variance, $\Delta R^{2}=.28, F(5,160)=20.07, p<.001$, and the schema theme of Worthiness emerged as the strongest predictor of depression symptoms in this multivariate context, accounting for $4 \%$ of unique variance in depression scores. Positive Schemas and Anxiety

The relation between positive schemas and anxiety. To analyze the hypothesis that there would be no global relation between positive schemas and anxiety, but an inverse relation with Self-Efficacy, several Pearson correlation analyses were examined (see Table 3). Contrary to hypotheses, a weak negative correlation was found between global positive schemas and anxiety scores. Furthermore, a significant negative relation was found between anxiety and Self-Efficacy, Success, Optimism, and Worthiness. No significant relationship was found between anxiety and Trust. 


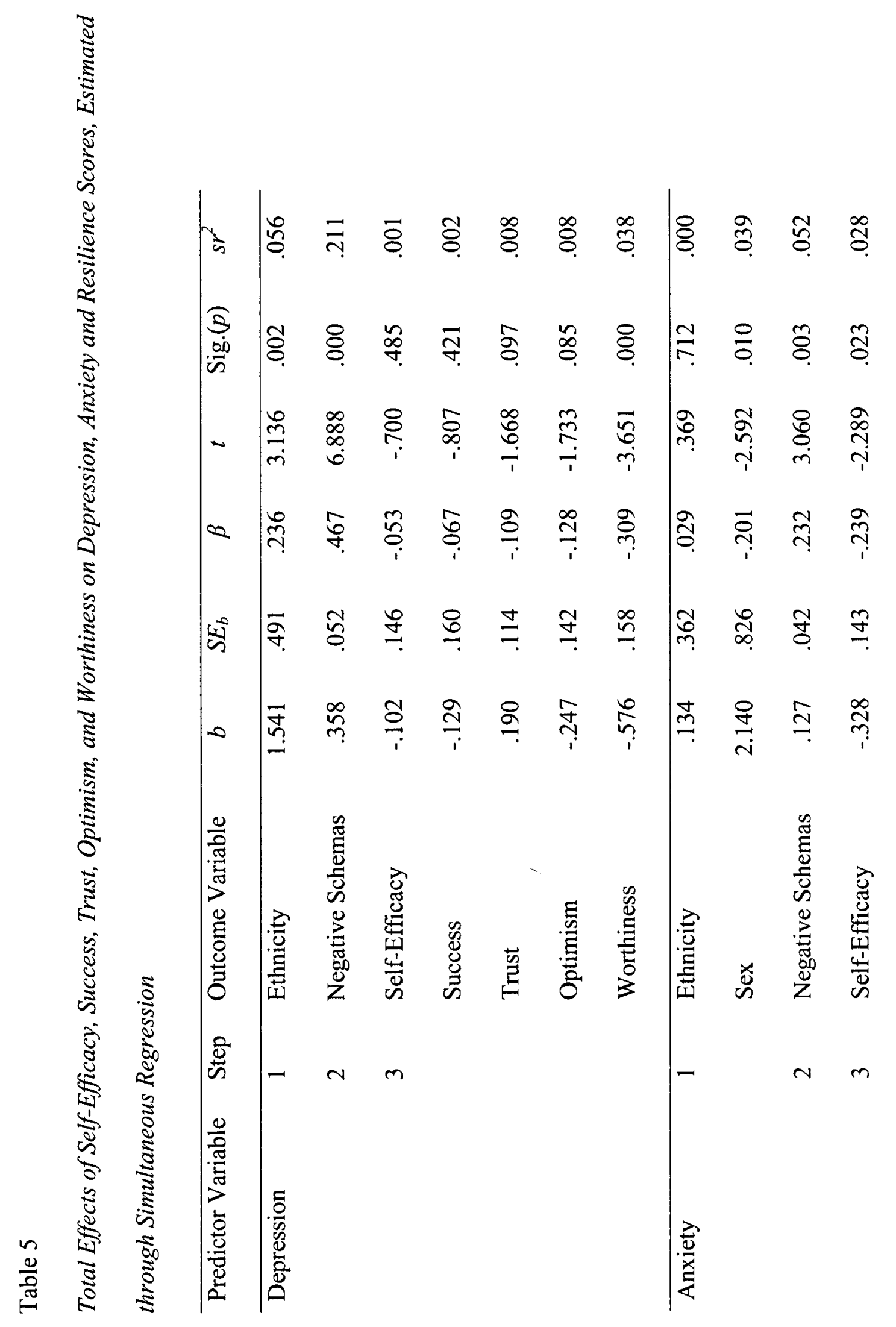




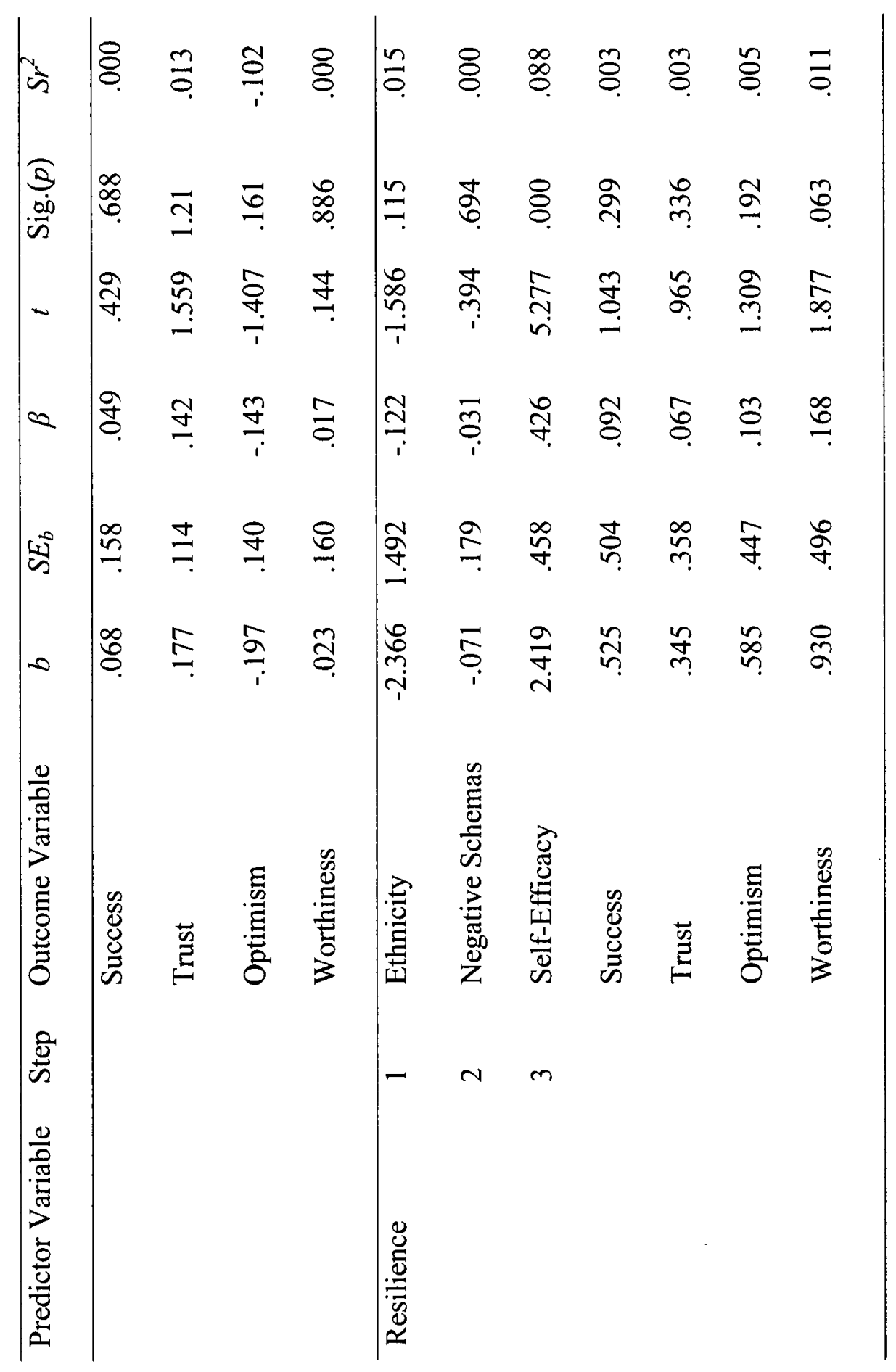


Unique contribution of positive schemas for predicting anxiety. To determine whether positive schemas explain additional significant variance in anxiety, beyond that explained by negative schemas, a hierarchical linear regression was conducted (see Table 4). For the regression analysis, the predictor variables were entered in three blocks: (1) ethnicity and sex, (2) negative schema total, and (3) positive schema total. In the first block, sex and ethnicity accounted for significant variance in anxiety, $\Delta R^{2}=.04, F(2,165)$ $=3.37, \mathrm{p}<.05$, and this relationship was accounted for by sex which explained $4 \%$ of the variance in anxiety. In the second block, negative schemas accounted for a statistically significant increase in the variance of anxiety, $\Delta R^{2}=.05, F(1,164)=9.37, p<.01$. In the third block of the regression, positive schemas accounted for a statistically significant increase in variance of anxiety, $\Delta R^{2}=.02, F(1,163)=4.37, p<.05$, indicating that positive schemas account for additional significant variance in anxiety beyond that explained by negative schemas.

The contribution of individual schema themes for predicting anxiety. Another hierarchical linear regression analysis was computed to evaluate the relative strengths of each schema theme in predicting anxiety (see table 5). The data were entered in three blocks: (1) ethnicity and sex (2) negative schema total, and (3) Self-Efficacy, Success, Trust, Optimism, and Worthiness. In the first block, sex and ethnicity accounted for significant variance in anxiety, $\Delta R^{2}=.04, \mathrm{~F}(2,165)=3.37, \mathrm{p}<.05$, and this relationship was accounted for by sex. In the second block, negative schemas accounted for a statistically significant increase in the variance of anxiety, $\Delta R^{2}=.05, F(1,164)=9.37, p$ $<.01$. The third block of this regression analysis was also significant, $\Delta R^{2}=.07, F(5,159)$ $=2.58, p<.05$, and the schema theme of Self-Efficacy emerged as the strongest predictor 
of anxiety symptoms in this multivariate context, accounting for $3 \%$ of unique variance in anxiety scores.

\section{Positive Schemas and Resilience}

The relation between positive schemas and resilience. To evaluate the hypotheses that global positive schemas, and positive schemas of various themes, would be positively related to child reported resilience, several Pearson correlation analyses were examined (see Table 3). Consistent with hypotheses, as global positive schemas increased so to did child-reported resilience. Furthermore, significant positive correlations were found between resilience and each positive schema theme, including Self-Efficacy, Success, Trust, Optimism, and Worthiness.

Unique contribution of positive schemas for predicting resilience. A hierarchical linear regression analysis was computed to determine whether positive schemas explain additional significant variance in resilience, beyond that explained by negative schemas. The predictor variables were entered in three blocks: (1) ethnicity, (2) negative schema total, and (3) positive schema total. Neither ethnicity, $\Delta R^{2}=.02, F(1,166)=2.52, p=.12$, nor negative schemas, $\Delta R^{2}=.00, F(1,165)=.16, p=.69$, accounted for significant variance in resilience scores; however, in the third step of the regression, positive schemas accounted for an increased $44 \%$ of variance in resilience, $\Delta R^{2}=.44, F(1,164)=$ $133.64 p<.001$ (see Table 4).

The contribution of individual schema themes for predicting resilience. To evaluate the relative strengths of each schema theme in predicting resilience scores, a hierarchical linear regression analysis was conducted. The data was entered in three blocks: (1) ethnicity (2) negative schema total (3) Self-Efficacy, Success, Trust, 
Optimism, and Worthiness. Neither ethnicity, $\Delta R^{2}=.02, F(1,166)=2.52, p=.12$, nor negative schemas, $\Delta R^{2}=.00, F(1,165)=69, p=.27$, accounted for significant variance in resilience scores; however, in the third step of the regression, positive schemas accounted for an increased $48 \%$ of variance in resilience, $\Delta R^{2}=.48, F(5,160)=30.55, p$ $<.001$. As evidenced in Table 5, the schema theme of Self-Efficacy emerged as the strongest predictor of resilience in this multivariate context, accounting for $9 \%$ of unique variance in resilience.

\section{Discussion}

The present study is the first to evaluate the role of specific positive schema themes in the development of psychopathology and resilience in children. The results provide convincing evidence that the Positive Schema Questionnaire is a promising tool that will be useful in the further evaluation of the role of positive schemas in child development. Factor analysis resulted in a 5-factor measure of positive schema themes including: Self-Efficacy, Success, Worthiness, Optimism, and Interpersonal Trust. This is the first unitary measure to evaluate core positive schema themes in children.

The current study's findings that positive schemas contribute significantly to the prediction of depression, anxiety, and resilience, beyond that explained by negative schemas, supports the theory that positive schemas exist on a separate continuum from negative schemas (e.g., MacLeod \& Moore, 2000), and underscores the importance of considering low levels of positive schemas as a diathesis to psychopathology.

Furthermore, the finding that specific positive schema themes arise as unique predictors of each outcome provides evidence that cognitive content specificity models (Beck, 1976) may also apply to positive schemas. Specifically, the current study provides 
evidence that the positive schema theme of worthiness is strongly linked to depression, while self-efficacy was the strongest predictor of anxiety symptoms and child-reported resilience. Together, these results emphasize the importance of greater incorporation of positive schemas into cognitive models of psychopathology. Results indicate that the PSQ may be a useful clinical tool for the early detection of depression and anxiety symptoms in children.

\section{Positive Schema Questionnaire}

A primary goal of the current investigation was to develop a psychometrically sound tool for assessing positive core schemas in youth, and the results of this first empirical examination provide convincing evidence of the PSQ's promise. The factor analysis supported 5 of the apriori schema categories including: Self-Efficacy, Success, Worthiness, Optimism, and Interpersonal Trust. Of note, these factors possess good face validity, and are significantly correlated with negative cognitive schemas and various measures of youth functioning including depression, anxiety, and resilience, in the directions supported by previous research. Furthermore, individual schema themes were found to have strong predictive validity and differentiated between various symptom profiles. Thus, this inventory is poised to be a very useful tool in future research aimed at understanding the role of specific positive schema themes as diatheses to psychopathology. Once these results are extended to a clinical sample, the PSQ may have important uses in clinical settings both to aid with assessment of youth vulnerability and to help direct therapeutic interventions. By learning about a child's positive schema profile, clinicians may gain important insight into the child's potential trajectory and unique areas of strength and vulnerability. 


\section{Positive Schemas and Depression}

In order to develop a more comprehensive understanding of the role of positive schemas and depression symptoms, the current study evaluated relations between global positive schemas and depression symptoms, as well as between specific schema themes and depression symptoms. I hypothesized that global positive schemas, as well as positive schemas of various themes, would be negatively related to depression, but that particular schema themes would uniquely contribute to vulnerability to depression. Consistent with hypotheses, global positive schemas, as well as particular schema themes of Worthiness, Optimism, Trust, Self-Efficacy, and Success, were all found to be significantly negatively related to depression scores in children. This finding is consistent with past research that demonstrated that low levels of global positive schemas are associated with depression outcomes in children (e.g., Jaenicke et al., 1987; Prieto et al., 1992; Shirk et al., 1998; Whitman \& Leitenberg, 1990) and is also supported by research demonstrating a negative relationship between depression and the schema themes' corresponding cognitive constructs (e.g., Bandura et al., 1999; Benhua \& Yanxiang, 2004; Chang, 1996; Cole et al., 1999; Garber \& Hilsman, 1992; Puskar et al., 1999; Williams \& Galliher, 2006).

Unlike much of this other research, a particular strength of the current study is the multivariate approach in which positive and negative schemas are jointly considered in models of risk. To ensure that positive schemas contribute to our understanding of cognitive vulnerability to depression, beyond that explained by negative schemas, the current study investigated whether positive schemas predicted any additional variance in depression scores, over that explained by negative schemas. Importantly, positive 
schemas predicted more variance in depression scores than negative schemas, specifically explaining an additional $28 \%$ of the variance. This finding is consistent with past research which highlights the important role of positive cognitive constructs in depression in youth (e.g., Whitman \& Leitenberg, 1990), and suggests that lacking sufficiently positive global self-schemas may at times act as a stronger predictor for depression in children than characteristic "negative cognitive bias." Thus, positive schemas may play an even more important role than negative schemas in the early detection of depression.

To evaluate which schema themes serve as the strongest diathesis for depression, the current study considered the unique role of each schema theme for predicting depressive symptoms. Consistent with hypotheses, Worthiness was found to be the strongest predictor of depression in children. This finding is consistent with research conducted by Cole et al. (2009) that found global self-worth to be the cognitive construct most highly associated with depressive symptoms in children, and is also supported by a large body of research that demonstrates that low levels of self-worth are strongly implicated in childhood depression (e.g., Cole et al., 1999; Garber \& Hilsman, 1992; Garber et al., 1997; Lumley \& Harkness, 2007). Interestingly, this result is also in line with Beck's content specificity hypothesis, which theorizes that low self-views are very characteristic of depression (Clark, Beck, \& Brown, 1989; Clark, Beck \& Stewart, 1990).

While positive schemas are theorized to lie on a separate continuum from negative schemas, positive schemas may influence the development of depression through similar mechanisms. In Beck's $(1967 ; 1987)$ theory of depression, he hypothesized that negative self-schemas of worthlessness are presented as dysfunctional self-worth contingencies. As such, when a person experiences a negative life event, he or 
she will interpret his/her experiences through this negative lens, resulting in a negatively biased interpretation of the self, world, and future. Positive schemas related to worthiness may also create vulnerability to depression through similar mechanisms. In this case, low positive schemas impact interpretations of positive events, with a lens that does not enable positive experiences to positively influence views of the self, the world, or the future. For example, if a person with a low worthiness schema receives a good grade at school, he or she likely will not internalize that experience, and may instead rationalize it in a way that discounts the positive experience. For example, he or she may have thoughts such as: "Even though I did well, it doesn't mean it's a reflection of my abilities." Thus, positive schemas may play a role in the etiology to depression by limiting one's experiences of positive self-appraisal.

While Worthiness was the only schema theme to emerge as a significant unique predictor of depression, the other positive schema themes, together explained a large portion of the variance in depression symptoms. Cognitive models of youth depression (see Abela \& Hankin, 2008) consistently highlight negative cognitive mechanisms that promote mood psychopathology. The results of this analysis strongly highlight the importance of incorporating positive schemas into these models to more fully illuminate the mechanisms of risk.

\section{Positive Schemas and Anxiety}

In order to develop a more comprehensive understanding of the role of positive schemas in the diathesis to anxiety, the current study evaluated relations between global positive schemas and anxiety, as well as between specific schema themes and anxiety outcomes. I hypothesized that no relation would exist between global positive schemas 
and anxiety, but that when looking at specific schema themes, Self-Efficacy would emerge as an important predictor of anxiety. Contrary to hypotheses, a weak negative relation was found between global positive schemas and anxiety symptoms. Supporting hypotheses and consistent with past research on cognitive constructs (e.g., Bogels \& Zigterman, 2000; Matsuo \& Arai, 1998; Muris, 2002; Yue, 1996), when examining relations between specific schema themes and anxiety, a weak negative relationship was found between Self-Efficacy and anxiety. Interestingly, the schema themes of Worthiness, Success, and Optimism were also found to be weakly related to anxiety symptoms.

To develop a clearer picture of the role of positive schema themes for predicting anxiety symptoms in youth, further analyses were conducted, taking into account the covariance between each of the schema themes with both other positive schema themes, as well as with negative schemas. Contradicting past research (e.g., e.g., MacLeod \& Byrne, 1996; MacLeod \& Salaminious, 2001; MacLeod et al., 1997) positive schemas predicted additional significant variance in anxiety scores beyond that explained by negative schemas. When the variance in anxiety scores attributed to negative schemas was removed, consistent with hypotheses, Self-Efficacy emerged as the only significant predictor of anxiety scores. Thus, the relationship between Self-Efficacy and anxiety might largely account for the relationship between positive schemas and anxiety. This finding is consistent with past research suggesting that cognitions related to coping selfefficacy, control, and self-mastery are related to anxiety outcomes in adult populations (e.g., Bogels \& Zigterman, 2000; Casey et al., 2004; Matsuo \& Arai, 1998; Muris, 2002; Schmidt et al., 1997; Stoler \& McNally, 1991; Telch et al., 1989; Yue, 1996). 
Taken together, these results contribute greatly to understanding of the positive cognitive vulnerability factors implicated in childhood anxiety symptoms, and suggest that cognitive theories of anxiety would benefit from incorporating positive schemas into models of risk. Theory has suggested that positive cognitions are not implicated in anxiety disorders and may help to differentiate anxiety from depression (e.g., Tripartite model; Clark \& Watson, 1991). The current results suggest that this may be due to consideration and evaluation of positive schemas on a global level, while ignoring the specific content of the schemas possessed by the individual. The current research suggests that for youth, strong negative and weak positive schemas act as vulnerability factors for both depression and anxiety; however, it is the specific positive schema themes that differentially predict the disorders, with schema themes of worthiness linked to depression and themes of self-efficacy linked to anxiety. Also, the magnitude of the relation between positive schemas and depression appears to be much stronger than positive schemas and anxiety.

In contrast to the tripartite model, but consistent with Beck et al.'s (1985) argument, the current study supports the theory that vulnerability to anxiety is a result of both the existence of negative schemas (surrounding danger), combined with a lack of positive schemas regarding one's ability to cope with or control the danger. When a youth has low self-efficacy, he/she is more likely to perceive situations as dangerous, due to his/her inability to properly cope with the situation.

\section{Positive Schemas and Resilience}

Lastly, an evaluation was conducted to examine relations between positive schemas and childhood resilience. I hypothesized that global positive schemas, as well as 
positive schemas of various themes would be positively related to resilience, and that particular schema themes would emerge as the most important predictors of childhood resilience. Consistent with hypotheses, a positive relation was found between global positive schemas, as well as particular schema themes and child-reported resilience. Youth who report stronger positive beliefs about self also report being able to overcome stressful or challenging situations. This finding is also consistent with theory that positively biased self-views in various cognitive domains, serve a protective role by allowing information to be filtered in a positive direction (e.g., Taylor \& Brown, 1988, 1994). Furthermore, this finding emphasizes that positive states not only signal positive functioning, but may also play an important role in facilitating future resilience (Diener \& Diener, 1996; Fredrickson, 2004; Fredrickson \& Joiner, 2002). Future prospective research will help to address this question more appropriately.

Intriguingly, negative schemas were not found to account for significant variance, while positive schemas were found to account for $48 \%$ of the variance in resilience scores. Importantly, having low levels of negative schemas is not sufficient for mental health, but rather it is positive schemas that are likely most instrumental in protecting against the development of psychopathology. Self-Efficacy was found to be the schema theme most central to resilience. Thus, one's belief in his/her own ability to control outcomes may increase one's ability to cope with adversity. Consistently, selfperceptions of efficacy have been theorized to influence the way one responds to adversity by impacting the way a person copes, appraises the situation, and later how he/she reacts emotionally (Bandura, 1982). The belief in one's ability to overcome obstacles impacts effort and persistence when faced with an aversive experience. This, in 
turn, impacts a person's thought patterns and emotional reactions when both anticipating and experiencing environmental challenges. For example, a person with low self-efficacy may focus on the inability to overcome a challenge, and this in turn will impair his/her performance, resulting in feelings of stress. Those with higher self-efficacy are more likely to use effort to react to the demands of the situation and as a result may not experience stress reactions.

If replicated in a clinical sample, the finding that global positive schemas as well as particular schema themes related to Self-Efficacy are strongly associated with childhood resilience may have important implications for therapy. These results emphasize the importance of a therapeutic focus not only on eliminating negative cognitions, but also on targeting the development of positive cognitions. While decreasing negative schemas through therapy may play an important role in decreasing aversive symptoms, the current results suggest it may not be sufficient to produce longterm mental health and resilient coping strategies in the face of future stressors.

\section{Limitations}

There are several limitations in the current study that provide important implications for future research. While the current study's aim was to evaluate how particular positive schema themes predict psychopathology and resilience, the evaluation of the predictor and outcome variables was conducted at one time point, negating the possibility of evaluating the theoretically implied causal relations. While it is possible that outcome variables of depression, anxiety, and resilience each preceded and impacted the development of positive schema patterns, given the consistent, persuasive evidence that negative schemas precede the development of psychopathology (e.g., Abela \& 
Hankin, 2008) the assumption that positive schemas precede the development of the outcome variables, is well grounded in research. Furthermore, the relation between psychopathology and schemas is likely bidirectional and evolving over time. As such, careful longitudinal research will be required to establish a clearer sense of the unfolding of these important relations in youth.

Another limitation of the current study was that the sample size was not sufficiently large to adequately evaluate gender, ethnicity, and age differences. In the current study, participants from ethnically diverse populations demonstrated significantly more negative schemas than Caucasian participants. Furthermore, ethnicity was found to account for significant variance in depression scores. This finding suggests that the higher negative schemas possessed by ethnically diverse individuals may result in these individuals being more vulnerable to depression. Furthermore, in an evaluation of sex differences, girls were found to display significantly more anxiety than boys, and sex accounted for significant variance in anxiety scores, indicating that girls may be more vulnerable to developing anxiety than boys. While it is suspected that significant ethnicity, sex and age differences exist in the development and presentation of positive schema themes, the current study did not have sufficient power to properly evaluate more fine-grained questions of risk and resilience. Future research should focus on evaluating ethnicity, gender and age differences in links between positive schemas, resilience and various forms of psychopathology.

Thirdly, evaluations of schemas, depression, anxiety, and resilience were all selfreport. While the CDI, MASC, and RS possess high degrees of reliability and validity, given the self-report nature of these assessments, scores on these measures may be 
impacted by mood or social desirability biases. Also, youth may lack the ability or desire to accurately identify and report on internal states. Although many researchers have highlighted the limitations of self-report for examining models of psychopathology risk (e.g., Segal, 1988), research also suggests that children may be the best reporters of their internalizing symptoms (Edelbrock, Costello, Dulcan, Conover, \& Kalas, 1986; Saylor, Finch, Baskin, Furey, \& Kelly, 1984). Future research would benefit from including observational measures, clinical interviews and more indirect measures of child functioning variables to capture a more comprehensive glimpse of the relation between positive schemas and psychopathology/resilience. Still, the current study's findings are convincing, as self-report bias cannot easily account for the finding that particular schema themes arose as more central to particular outcomes. Also, it is children's perceptions that are valued as a key aspect of this inquiry.

Finally, given that the present study was conducted with a community-based sample, the findings of this study may not apply to clinical populations. The majority of participants in this study only experienced sub-clinical levels of depression and anxiety, and thus, the same patterns may not exist within children with more severe symptoms. Still, the current study provides very important information regarding the factors that play a role in the early stages of depression and anxiety in children, as sub-clinical levels of depression and anxiety are strong predictors of developing clinical symptoms (e.g., Harrington, Fudge, Rutter, Pickles, \& Hill, 1990).

\section{Conclusions}

The current study evaluates a new positive schema measure for youth, the Positive Schema Questionnaire. The PSQ appears to be a useful research tool for evaluating how 
positive schemas of Self-Efficacy, Worthiness, Optimism, Success, and Interpersonal Trust are differentially related to various forms of psychopathology and resilience. This study provides convincing evidence that positive schemas predict significant variance in depression, anxiety, and resilience in children, beyond that explained by negative schemas. Furthermore, the current study provides evidence that the content specificity model as envisioned for negative schemas may also apply to positive schemas, with the theme of Worthiness most predictive of depression and the theme of Self-Efficacy most predictive of anxiety and resilience.

Together, these findings have several important implications. Findings that positive schemas predict additional variance in childhood outcomes emphasize the importance of incorporating positive schemas into cognitive models of psychopathology. The finding that positive schemas appear to be a stronger predictor of depression symptoms than negative schemas indicates that positive schemas may play an even more important role than negative schemas in the early detection of what for many youth develops into chronic mood psychopathology. The current study contributes to the understanding of vulnerability to depression and anxiety by demonstrating that these commonly comorbid states may be differentiated, not based on the presence or absence of positive schemas, but rather based on strength of the positive schema theme the child possesses (i.e., Worthiness for depression and Self-Efficacy for anxiety).

Although caution must be taken when applying this community research to clinical populations, this research also has several possible clinical implications. First, this research suggests that finding ways to promote positive schema development in youth may have implications for prevention of psychopathology. Also, findings suggest 
that building positive schemas within therapy may be an important component of treatment for depression and anxiety, and will be essential for developing childhood resilience in the face of future stressors. Future research focused on developing an increased understanding of how positive schema themes and negative schema themes interact to produce vulnerability for community and clinical populations is an important area of study as theoretical models of risk are expanded to include more emphasis on positive cognitive variables. 


\section{References}

Abela, J. R. Z., \& Hankin, B. L. (2008). Depression in children and adolescents: Causes, treatment and prevention. In J. R. Z. Abela, \& B. L. Hankin (Eds.), Handbook of child and adolescent depression (pp. 3-5). New York: The Guilford Press.

Abela, J. R., Zinck, S., Kryger, S., Zilber, I., \& Hankin, B. L. (2009). Contagious depression: Negative attachment cognitions as a moderator of the temporal association between parental depression and child depression. Journal of Clinical Child Adolescent Psychology, 38(1), 16-26.

Abramson, L. Y., \& Alloy, L. B. (1981). Depression, non-depression, and cognitive illusions: A reply to Schwartz. Journal of Experimental Psychology, 110, 436-447.

Achat, H., Kawachi, I., Spiro, A., DeMolles, D., \& Sparrow, D. (2000). Optimism and depression as predictors of physical and mental health functioning: The normative aging study. The Society of Behavioral Medicine, 22(2), 127-130.

Affleck, G., \& Tennen, H. (1996). Construing benefits from adversity: Adaptational significance and dispositional underpinnings. Journal of Personality, 64(4), 900922.

Andersson, G. (1996). The benefits of optimism: A meta-analytic review of the Life Orientation Test. Personality Individual Differences, 21(5), 719-725.

Armstrong, S., \& Oomen-Early, J. (2009). Social connectedness, self-esteem and depression symptomatology among collegiate athletes versus non-athletes. Journal of American College Health, 57(5), 521-526.

Bandura, A. (1988). Self-efficacy conception of anxiety. Anxiety Research, 1, 77-98.

Bandura, A. (1991). Self-regulation of motivation through anticipatory and self- 
regulatory mechanisms. In R. A. Dienstbier (Ed.), Perspectives on motivation: Nebraska symposium on motivation (Vol. 38, pp. 69-164). Lincoln: University of Nebraska Press.

Bandura, A. (1993). Perceived self-efficacy in cognitive development and functioning. Educational Psychologist, 28(2), 117-148.

Bandura, A., Pastorelli, C., Barbaranelli, C., \& Caprara, G. V. (1999). Self-efficacy pathways to childhood depression. Personality Processes and Individual Differences, 76(2), 258-269.

Beck, A. T. (1967). Depression: Causes and treatment. Philadelphia, PA: University of Pennsylvania Press.

Beck, A. T. (1976). Cognitive therapy and the emotional disorders. New York: Basic Books.

Beck, A. T. (1982). Self-efficacy mechanisms in human agency. American Psychologist, $37(2), 122-147$.

Beck, A. T. (1983). Cognitive therapy of depression: New perspectives. In P. J. Clayton \& J. E. Barrett (Eds.). Treatment of depression: Old controversies and new approaches (pp. 265-290). New York: Raven Press.

Beck, A. T. (1987). Cognitive models of depression. Journal of Cognitive Psychotherapy: An International Quarterly, 1, 5-37.

Beck, A. T., \& Clark, D. A. (1988). Anxiety and depression: An information processing perspective. Anxiety Research, 1, 23-36.

Beck, A. T., Emery, G., \& Greenberg, R. L. (1985). Anxiety disorders and phobias: A cognitive perspective. New York: Basic Books. 
Beck, A. T., Rush, A. J., Shaw, B. F., \& Emery, G. (1979). Cognitive therapy of depression. New York: Guilford.

Beck, A. T., Steer, R. A., \& Epstein, N. (1992). Differentiating anxiety and depression: A test of the cognitive content-specificity hypothesis. Journal of Clinical Psychology, 48, 423-432.

Bell-Dolan, D. J., Reaven, N. M., \& Peterson, L. (1993). Child depression and social functioning: A multidimensional study of the linkages. Journal of Clinical Child Psychology, 22, 306-315.

Benhua, X., \& Yanxiang, P. (2004). Research on the relationship between interpersonal trust and depression of undergraduate. Journal of Clinical Psychosomatic Disease, 2.

Blechman, E. A., McEnroe, M. J., Carella, E. T., \& Audette, D. P. (1986). Childhood competence and depression. Journal of Abnormal Psychology, 95(3), 223-227.

Bogels, S. M., \& Zigterman, D. (2000). Dysfunctional cognitions in children with social phobia, separation anxiety disorder, and generalized anxiety disorder. Journal of Abnormal Child Psychology, 28(2), 205-211.

Cacioppo, J. T., Gardner, W. L., \& Berntson, G. G. (1999). The affect system has parallel and integrative processing components: Form follows function. Journal of Personality and Social Psychology, 76, 839-855.

Carey, M. P., Faulstich, M. E., Gresham, F. M., Ruggiero, L., \& Enyart, P. (1987).

Children's depression inventory: Construct and discriminant validity across clinical and non-referred (control) populations. Journal of Consulting and Clinical Psychology, 55(5), 755-761. 
Carver, C. S., \& Gaines, J. G. (1987). Optimism, pessimism, and post-partum depression. Cognitive Therapy and Research, $11,449-461$.

Casey, L., Oei, T., \& Newcombe, P. (2004). An integrated cognitive model of panic disorder: The role of positive and negative cognitions. Clinical Psychology Review, 24, 529-555.

Casey, L., Oei, T., Newcombe, P., \& Kenardy, J. (2004). The role of catastrophic misinterpretation of bodily sensations and panic self-efficacy in predicting panic severity. Clinical Psychology Review, 18, 325-340.

Cecero, J., Nelson, J. D., \& Gillie, J. M. (2004). Tools and tenets of schema therapy: Toward the construct validity of the Early Maladaptive Schema Questionnaireresearch version (EMSQ-R). Clinical Psychology and Psychotherapy, 11, 344357.

Chang, E. C. (1996). Cultural differences in optimism, pessimism, and coping: Predictors of subsequent adjustment in Asian American and Caucasian American students. Journal of Counseling Psychology, 43, 113-123.

Clark, D. M. (1993). Cognitive mediation of panic attacks induced by biological challenge tests. Special issue: Panic, cognitions and sensations. Advances in Behaviour Research and Therapy, 15, 75-84.

Clark, D. A., Beck, A. T., \& Brown, G. (1989). Cognitive mediation in general psychiatric outpatients: A test of the content-specificity hypothesis. Journal of Personality and Social Psychology, 56(6), 958-964.

Clark, D. A., Beck, A. T., \& Stewart, B. L. (1990). Cognitive specificity and positivenegative affectivity: Complementary or contradictory views on anxiety and 
depression? Journal of Abnormal Psychology, 99, 148-155.

Clark, D. A., Steer, R. A., \& Beck, A. T. (1994). Common and specific dimensions of self-reported anxiety and depression: Implications for the cognitive and tripartite models. Journal of Abnormal Psychology, 103, 645-654.

Clark, L. A., \& Watson, D. (1991). Tripartite model of anxiety and depression: Psychometric evidence and taxonomic implications. Journal of Abnormal Psychology, 100(3), 316-336.

Clark, L. A., Watson, D., \& Mineka, S. (1994). Temperament, personality, and the mood and anxiety disorders. Journal of Abnormal Psychology, 103, 103-116.

Clum, G., Watkins, P., Borden, J., Broyles, S., \& Hayes, J. (1993). A comparison of guided imaginal coping and imaginal exposure in the treatment of panic disorder. Journal of Rational-Emotive and Cognitive-Behavioral Therapy, 11(4), 179-193.

Cole, D. A. (1991). Preliminary support for a competency-based model of depression in children. Journal of Abnormal Psychology, 100(2), 181-190.

Cole, D. A., Jacquez, F. M., Truss, A. E., Pineda, A. Q., Weitauf, A. S., TilghmanOsborne, C. E., Felton, J. W., \& Maxwell, M. A. (2009). Gender differences in the longitudinal structure of cognitive diatheses for depression in children and adolescents. Journal of Clinical Psychology, 65(12), 1312-1326.

Cole, D. A., Martin, J. M., Peeke, L. A., Seroczynski, A. D., \& Fier, J. (1999). Children's over- and underestimation of academic competence: A longitudinal study of gender differences, depression, and anxiety. Child Development, 70, 459-473.

Cole, D. A., Martin, J. M., Peeke, L. G., Seroczynski, A. D., \& Hoffman, K. (1998). Are cognitive errors of underestimation predictive or reflective of depressive 
symptoms in children: A longitudinal study. Journal of Abnormal Psychology, 107, 481-496.

Colvin, R., \& Block, J. (1994). Do positive illusions foster mental health? An examination of the Taylor and Brown formulation. Psychological Bulletin, 116(1), 3-20.

Colvin, R., Block, J., \& Funder, D. (1995). Overly positive self-evaluations and personality: Negative implications for mental health. Journal of Personality and Social Psychology, 68(6), 1152-1162.

Costello, A. B., \& Osborne, J. W. (2005). Best practices in exploratory factor analysis: Four recommendations for getting the most from your analysis Practical Assessment. Research \& Evaluation, 10(7), 1-9.

Cote, G., Gauthier, J. G., Laberge, B., \& Cormier, H. J. (1994). Reduced therapist contact in the cognitive behavioral treatment of panic disorder. Behavior Therapy, 25, 123145.

Coyne, J. C., \& Gotlieb, I. H. (1983). The role of cognition in depression: A critical appraisal. Psychological Bulletin, 94, 472-505.

Dewberry, C., \& Richardson, S. (1990). Effect of anxiety on optimism. The Journal of Social Psychology, 130(6), 731-738.

Diener, E., \& Diener, C. (1996). Most people are happy. Psychological science, 7(3),181185.

Dykman, B. M., Abramson, L. Y., Alloy, L. B., \& Hartlage, S. (1989). Processing of ambiguous and unambiguous feedback by depressed and nondepressed college students: Schematic biases and their implications for depressive realism. Journal of 
Personality and Social Psychology, 56, 431-445.

Edelbrock, D., Costello, A. J., Dulcan, M. K., Conover, N. C., \& Kalas, R. (1986).

Parent-child agreement on child psychiatric symptoms assessed via structured interview. Journal of Child Psychology and Psychiatry, 27, 181-190.

Epkins, C. C. (2000). Cognitive specificity in internalizing and externalizing problems in community and clinic-referred children. Journal of Clinical Child Psychology, 29(2), 199-208.

Fauber, R., Forehand, R., Long, N., Burke, M., \& Faust, J. (1986). The relationship of young adolescent Children's Depression Inventory (CDI) scores to their social and cognitive functioning. Journal of Psychopathology and Behavioural Assessment, $9(2), 161-172$.

Feshbach, N. D., \& Feshbach, S. (1987). Affective processes and academic achievement. Child Development, 58, 1335-1347.

Fleming, J., \& Darley, J. M. (1986). Perceiving intention in constrained behavior: The role of purposeful and constrained action cues in correspondence bias effects. Unpublished manuscript, Princeton University.

Floyd, F. J., \& Widaman, K. F. (1995). Factor analysis in the development and refinement of clinical assessment instruments. Psychological Assessment, 7(3), 286299.

Folkman, S., \& Moskowitz, J. T. (2000). Positive affect and the other side of coping. American Psychologist, 55(6), 647-654.

Ford, J. K., MacCallum, R. C., \& Tait, M. (1986). The application of exploratory factor analysis in applied psychology: A critical review and analysis. Personnel 
Psychology, 39, 291-314.

Fredrickson, B. (2000). Cultivating positive emotions to optimize health and well-being.

Prevention and Treatment, 3. Retrieved June 18, 2010, from http://journals.aoa.org/ prevention/volume3/pre0030001a.html.

Fredrickson, B. (2004). The broaden-and-build theory of positive emotions.

Philosophical Transactions of the Royal Society, 359, 1367-1377.

Fredrickson, B. L. \& Joiner, T. (2002). Positive emotions trigger upward spirals toward emotional well-being. Psychological Science, 13, 172-175.

Garber, J., \& Hilsman, R. (1992). Cognitions, stress, and depression in children and adolescents. Child and Adolescent Psychiatric Clinics of North America, 1, 129167.

Garber, J., Robinson, N. S., \& Valentiner, D. (1997). The relation between parenting and adolescent depression: self-worth as a mediator. Journal of Adolescent Research, $12(1), 12-33$.

Gerbing, D. W., \& Hamilton, J. G. (1996). Viability of exploratory factor analysis as a precursor to confirmatory factor analysis. Structural Equation Modeling. 3(1), $62-$ 72.

Gibb, B. E., \& Abela, J. R. (2008). Emotional abuse, verbal victimization, and the development of children's negative inferential styles and depressive symptoms. Cognitive Theory Research, 32, 161-176.

Golin, S., Terrell, F., \& Johnson, B. (1977). Depression and the illusion of control. Journal of Abnormal Psychology, 86, 440-442.

Golin, S., Terrell, T., Weitz, J., \& Drost, E. L. (1979). The illusion of control among 
depressed patients. Journal of Abnormal Psychology, 88, 454-457.

Greenberg, M. S., \& Beck, A. T. (1989). Depression versus anxiety: A test of the content specificity hypothesis. Journal of Abnormal Psychology, 98, 9-13.

Greenwald, A. G. (1980). The totalitarian ego: Fabrication and revision of personal history. American Psychologist, 35, 603-618.

Hammen, C., \& Zupan, B. (1984). Self-schemas, depression, and the processing of personal information in children. Journal of Environmental Child Psychology, 37, 598-608.

Hankin, B. L., \& Abela, J. R. Z. (2005). Depression from childhood to adolescence and adulthood: A developmental vulnerability and stress perspective. In B. L. Hankin \& J. R. Z. Abela (Eds.), Development of psychopathology: A vulnerability-stress perspective (pp. 385-416). Thousand Oaks, CA: Sage.

Hankin, B. L., \& Abramson, L. Y. (2001). Development of gender differences in depression: An elaborated cognitive vulnerability-transactional stress theory. Psychological Bulletin, 127, 773-796.

Harmelen, A. Jong, P. J., Glashouwer, K. A., Spinhoven, P., Pinninx, B. W., \& Elzinga, B. M. (2010). Child abuse and negative explicit and automatic self-associations: The cognitive scars of emotional maltreatment. Behaviour Research and Therapy, $48,486-494$

Harrington, R. C., Fudge, H., Rutter, M., Pickles, A., \& Hill, J. (1990). Adult outcome of childhood and adolescent depression: I. Psychiatric status. Archives of General Psychiatry, 47, 465-473.

Hays, R. (1974). Expatriate Selection: Insuring Success and Avoiding Failure. Journal of 
International Business Studies, 5(1), 25-37.

Jaenicke, C., Hammen, C., Zupan, B., Hiroto, D., Gordon, D., Adrian, C., \& Burge, D. (1987). Cognitive vulnerability in children at risk for depression. Journal of Abnormal Child Psychology, 15, 559-572.

James, I. A., Reichelt, F. K., Freeston, M. H., \& Barton, S. B. (2007). Schemas as memories: Implications for treatment. Journal of Cognitive Psychotherapy: An International Quarterly, 21, 51-57.

Jolly, J. B. (1993). A multi-method test of the cognitive content-specificity hypothesis in young adolescents. Journal of Anxiety Disorders, 7, 223-233.

Kendall, P. C., \& MacDonald, J. P. (1993). Cognitions in the psychopathology of youth and implications for treatment. In K. S. Dobson \& P. C. Kendall (Eds.), Psychopathology and cognition (pp. 387-427). San Diego, CA: Academic Press.

Kercher, A., Rapee, R., \& Schniering, C. (2009). Neuroticism, life events and negative thoughts in the development of depression in adolescent girls. Journal of Abnormal Child Psychology, 37, 903-915.

Kovacs, M. (1981). Rating scales to assess depression in school-aged children. Acta Paedopsychiatry, 46, 305-315.

Lakdawalla, Z., Hankin, B. L., \& Mermelstein, R. (2007). Cognitive theories of depression in children and adolescents: A conceptual and quantitative review. Clinical Child and Family Psychology, 10, 1- 24.

Langer, E. J., \& Roth, J. (1975). Heads I win, tails it's chance: The illusion of control as a function of the sequence of outcomes in a purely chance task. Journal of Personality and Social Psychology, 32, 951- 955. 
Lee, R. M., Draper, M., \& Lee, S. (2001). Social connectedness, dysfunctional interpersonal behaviors, and psychological distress: Testing a mediator model. Journal of Counseling Psychology, 48(3), 310-318.

Lee, R. M. \& Robins, S. B. (1995). Measuring belongingness: The social connectedness and social assurance scales. Journal of Counseling Psychology, 42, 232-241.

Lefkowitz, M. M., \& Tesiny, E. P. (1980). Assessment of child depression. Journal of Consulting and Clinical Psychology, 48, 43-50.

Lester, D., \& Gatto, J. (1990). Interpersonal trust, depression, and suicidal ideation in teenagers. Psychol Rep, 67, 786.

Lewicki, R. J., McAllister, D. J., \& Bies, R. J. (1998). Trust and distrust: New relationships and realities. Academy of Management Review, 23, 438-458.

Lewinsohn, P. M., Joiner, t. E., \& Rohde, P. (2001). Evaluation of cognitive-diathesisstress models in predicting major depressive disorder in adolescents. Journal of Abnormal Psychology, 110(2), 203-215.

Lidren, D. M., Watkins, P. L., Gould, R. A., Clum, G. A., Asterino, M., \& Tulloch, H. (1994). A comparison of bibliotherapy and group therapy in the treatment of panic disorder. Journal of Consulting and Clinical Psychology, 62, 865-869.

Lumley, M. N., \& Harkness, K. L. (2007). Specificity in the relations among childhood adversity, early maladaptive schemas, and symptom profiles in adolescent depression. Cognitive Theory Research, 31, 639-657.

MacLeod, A. \& Byrne, A. (1996). Anxiety, depression, and the anticipation of future positive and negative experiences. Journal of Abnormal Psychology, 105(2), 286289. 
MacLeod, L., Byrne, A., \& Valentine, J. D. (1996). Affect, emotional disorder, and future directed thinking. Cognition and Emotion, 10(1), 69-86.

MacLeod, A., \& Moore, R. (2000). Positive thinking revisited: Positive cognitions, wellbeing and mental health. Clinical Psychology and Psychotherapy, 7, 1-10.

MacLeod, A., Rose, G., \& Williams, M. (1993). Components of hopelessness about the future in parasuicide. Cognitive Therapy and Research, 17(5), 441-455.

MacLeod, A., \& Salaminiou, E. (2001). Reduced positive future-thinking in depression: Cognitive and affective factors. Cognition and Emotion, 15(1), 99-107.

MacLeod, A., Tata, P., Kentish, J., \& Jacobsen, H. (1997). Retrospective and prospective cognition in anxiety and depression. Cognition and Emotion, 11(4), 467-479.

Many, M., \& Many, W. (1975). The relationship between self-esteem and anxiety in grades four through eight. Educational and Psychological Measurement, 35(4), 1017-1021.

March, J. S. (1997). Multidimensional Anxiety Scale for Children: Technical manual. Toronto, ON: Multi-Health Systems.

March, J.S., Sullivan, K., \& Parker, J. (1999). Test-retest reliability of the Multidimensional Anxiety Scale for Children. Journal Anxiety Disorder, 13, 349358.

Marshall, G., \& Lang, E. (1990). Optimism, self-mastery, and symptoms of depression in women professionals. Journal of Personality and Social Psychology, 59(I), 132139.

Marshall, G. N., Wortman, C. B., Kusulas, J. W., Hervig, L. K., \& Vickers, R. R. (1992). Distinguishing optimism from pessimism: Relations to fundamental dimensions of 
mood and personality. Journal of Personality and Social Psychology, 62(6), 10671074.

Matsuo, N., \& Arai, K. (1998). Relationship among social anxiousness, public selfconsciousness, and social self-efficacy in children. Japanese Journal of Educational Psychology, 46, 21-30.

McClain, L., \& Abramson, L. (1995). Self-schemas, stress, and depressed mood in college students. Cognitive Therapy and Research, 19(4), 419-432

Miller, D. T., \& Ross, M. (1975). Self-serving biases in attribution of causality: Fact or fiction? Psychological Bulletin, 82, 213-225.

Muris, P. (2002). Relationships between self-efficacy and symptoms of anxiety disorders and depression in a normal adolescent sample. Personality and Individual Differences, 32, 337-348.

Muris, P. (2006). Maladaptive schemas in non-clinical adolescents: Relations to perceived parental rearing behaviours, big five personality factors and psychopathological symptoms. Clinical Psychology and Psychotherapy, 13, 405413.

Muris, P., \& Heiden, S. (2006). Anxiety, depression, and judgments about the probability of future negative and positive events in children. Journal of Anxiety disorders, 20(2), 252-261.

Neverlien, P., \& Johnsen, T. (1991). Optimism-pessimism dimension and dental anxiety in children. Community Dentistry and Oral Epidemiology, 19(6), 342-346.

Prieto, S., Cole, D., \& Tageson, W. (1992). Depressive self-schemas in clinic and nonclinic children. Cognitive Therapy and Research, 16(5), 521-533. 
Puskar, K. R., Sereika, S. M., Lamb, J., Tusaie-Mumford, K., \& Mcginness, T. (1990). Optimism and its relationship to depression, coping, anger, and life events in rural adolescents. Issues in Mental Health, 20, 115-130.

Rachman, S. J. (1990). Fear and courage. (2nd ed.). New York: W. H. Freeman.

Rousseau, D. M., Sitkin, S. B., Burt, R. S., \& Camerer, C. (1998). Not so different after all: A cross-discipline view of trust. Academy of Management Review, 23(3), 393404.

Rubin, K. H., Chen, X., McDougall, P., Bowker, A., \& McKinnon, J. (1995). The Waterloo Longitudinal Project: Predicting adolescent internalizing and externalizing problems from early and mid-childhood. Developmental Psychopathology, 7, 751-764.

Ruehlman, L. S., West, S. G., \& Pasahow, R. J. (1985). Depression and evaluative schemata. Journal of Personality, 53, 46-92.

Saylor, C. F., Finch, A. J., Baskin, C. H., Furey, W., \& Kelly, M. M. (1984). Construct validity for measures of childhood depression: application of multitraitmultimethod methodology. Journal of Consulting and Clinical Psychology, 52(6), 977-985

Scheier, M. F, \& Carver, C. S. (1985). Optimism, coping, and health: Assessment and implications of generalized outcome expectancies. Health Psychology, 4, 219-247.

Scheier, M. F., \& Carver, C. S. (1992). Effects of optimism on psychological and physical well-being: Theoretical overview and empirical update. Cognitive Therapy and Research, 16, 201-228.

Schmidt , N. B., Schmidt, K. L., \& Young, J. E. (1999). Schematic and interpersonal 
conceptualizations of depression: An integration In T. Joiner \& J. C. Coyne (Eds.), The interactional nature of depression (pp. 127 -48). Washington, DC: American Psychological Association.

Schmidt, N. B., Trakowski, J. H., \& Staab, J. P. (1997). Extinction of panicogenic effects of a $35 \% \mathrm{CO} 2$ challenge in patients with panic disorder. Journal of Abnormal Psychology, 106(4), 630-638.

Shirk, S., Boergers, J., Eason, A., \& Van Horn, M. (1998). Dysphoric interpersonal schemata and preadolescents' sensitization to negative events. Clinical Child and Adolescent Psychology, 27(1), 54-68.

Simmons, J., Cooper, M. J., Drinkwater, J., \& Stewart, A. (2006). Cognitive schemata in depressed adolescent girls and their mothers. Behavioural and Cognitive Psychotherapy, 34, 219-232.

Smith, T., Pope, M., Rhodewalt, F., \& Poulton, J. (1989). Optimism, neuroticism, coping and symptom reports: An alternative interpretation of the Life Orientation Test. Journal of Personality and Social Psychology, 56(4), 640-648.

Solberg, L., \& Segerstrom, S. (2006). Dispositional optimism and coping: A metaanalytic review. Personality and Social Psychology Review, 10(3), 235-251.

Stallard, P. (2007). Early maladaptive schemas in children: Stability and differences between a community and a clinic referred sample. Clinical Psychology and Psychotherapy, 14, 10-18.

Stallard, P., \& Rayner, H. (2005). The development and preliminary evaluation of a Schema Questionnaire for Children (SQC). Behavioural and Cognitive Psychotherapy, 33, 217-224. 
Stoler, L. S., \& McNally, R. J. (1991). Cognitive bias in symptomatic and recovered agoraphobics. Behaviour Research and Therapy, 29, 539-545.

Taylor, S. E., \& Brown, J. D. (1988). Illusion and well-being: A social psychological perspective on mental health. Psychological Bulletin, 103(2), 193-210.

Taylor, S. E., \& Brown, J. D. (1994). Positive illusions and well-being revisited separating fact from fiction. Psychological Bulletin, 116(1), 21-27.

Telch, M. J., Brouillard, M., Telch, C. F., Agras, W. S., \& Taylor, C. B. (1989). Role of cognitive appraisal in panic related avoidance. Behaviour Research and Therapy, 27(4), 373-383.

Treadwell, K. R. H., \& Kendall, P. C. (1996). Self-talk in youth with anxiety disorders: State of mind, content specificity, and treatment outcome. Journal of Consulting and Clinical Psychology, 6(5), 941-950.

Vlierberghe, L. V., Timbremont, B., Braet, C., \& Basile, B. (2007). Parental schemas in youngsters referred for antisocial behaviour problems demonstrating depressive symptoms. The Journal of Forensic Psychiatry \& Psychology, 18(4), 515-533.

Wagnild, G. M., \& Young, H. M. (1993). Development and psychometric evaluation of the Resilience Scale. Journal of Nursing Measurement, l, 165-178.

Watson, D., \& Clark, L. A. (1984). Negative affectivity: The disposition to experience aversive emotional states. Psychological Bulletin, 96, 465-490.

Whitman, P., \& Leitenberg, H. (1990). Negatively biased recall in children with selfreported symptoms of depression. Journal of Abnormal Child Psychology, 18(1), $15-27$.

Williams, S. L., \& Falbo, J. (1996). Cognitive and performance-based treatments for 
panic attacks in people with varying degrees of agoraphobic disability. Behavior Research and Therapy, 34, 253-264.

Williams, K., \& Galliher, R. (2006). Predicting depression and self-esteem from social connectedness, support, and competence. Journal of Social and Clinical Psychology, 25(8), 855-874.

Williams, S. L., \& Zane, G. (1989). Guided mastery and stimulus exposure treatments for severe performance anxiety in agoraphobics. Behavior Research and Therapy, $27(3), 237-245$.

Wood, R., \& Bandura, A. (1989). Impact of conceptions of ability on self-regulatory mechanisms and complex decision making. Journal of Personality and Social Psychology, 56(3), 407-415.

Young, J. E. (1990). Cognitive therapy for personality disorders: A schema-focused approach. Sarasota, FL: Professional Resource Exchange, Inc.

Young, J. E. (1991). Early Maladaptive Schemas. Unpublished manuscript.

Young, J. E. (1994). Cognitive therapy for personality disorders: A schema-focused approach (rev. ed.) Sarasota, FL: Professional Resource Press.

Young, J. E. (1999). Cognitive therapy for personality disorders: A schema-focused approach (3rd ed.). Sarasota, FL: Professional Resource Press.

Young, J. E., Klosko, J. S., \& Weishaar, M. E. (2003). Schema therapy: A practitioner's guide. New York: Guilford.

Yue, X. (1996). Test anxiety and self-efficacy: levels and relationship among secondary school students in Hong Kong. Psychologia: An International Journal of Psychology in the Orient, 39, 193-202. 


\section{Appendix A}

Positive Schema Questionnaire

Instructions: Please read the following statements. To the right of each you will find six numbers, ranging from " 1 " (Completely untrue of me) on the left to "6" (Describes me perfectly) on the right. Choose the number which best indicates how much you believe each statement is true for you.

\begin{tabular}{|c|c|c|c|c|c|}
\hline 1 & 2 & 3 & 4 & 5 & 6 \\
\hline $\begin{array}{c}\text { Completely } \\
\text { untrue of me }\end{array}$ & & & & & $\begin{array}{c}\text { Describes me } \\
\text { perfectly }\end{array}$ \\
\hline
\end{tabular}

\begin{tabular}{|r|l|l|l|l|l|l|l|}
\hline 1. & I look at the bright side of things & 1 & 2 & 3 & 4 & 5 & 6 \\
\hline 2. & I am close to other people & 1 & 2 & 3 & 4 & 5 & 6 \\
\hline 3. & I believe in myself & 1 & 2 & 3 & 4 & 5 & 6 \\
\hline 4. & I feel I can depend on people to keep my secrets & 1 & 2 & 3 & 4 & 5 & 6 \\
\hline 5. & I can achieve anything I set my mind to & 1 & 2 & 3 & 4 & 5 & 6 \\
\hline 6. & I can overcome the challenges I face & 1 & 2 & 3 & 4 & 5 & 6 \\
\hline 7. & I believe things will turn out well & 1 & 2 & 3 & 4 & 5 & 6 \\
\hline 8. & I feel loved by other people & 1 & 2 & 3 & 4 & 5 & 6 \\
\hline 9. & I deserve good things to happen to me & 1 & 2 & 3 & 4 & 5 & 6 \\
\hline 10. & I feel comfortable depending on other people & 1 & 2 & 3 & 4 & 5 & 6 \\
\hline 11. & I have the ability to be successful & 1 & 2 & 3 & 4 & 5 & 6 \\
\hline 12. & I can deal well with difficult situations & 1 & 2 & 3 & 4 & 5 & 6 \\
\hline 13. & I know how to find something good in every situation & 1 & 2 & 3 & 4 & 5 & 6 \\
\hline 14. & I have people I can share my secrets with & 1 & 2 & 3 & 4 & 5 & 6 \\
\hline 15. & I think I have many good qualities & 1 & 2 & 3 & 4 & 5 & 6 \\
\hline 16. & I trust other people & 1 & 2 & 3 & 4 & 5 & 6 \\
\hline 17. & I will accomplish my goals & 1 & 2 & 3 & 4 & 5 & 6 \\
\hline 18. & I can adapt to new situations & 1 & 2 & 3 & 4 & 5 & 6 \\
\hline 19. & I usually see the positive side of things & 1 & 2 & 3 & 4 & 5 & 6 \\
\hline 20. & Other people make me feel good about myself & 1 & 2 & 3 & 4 & 5 & 6 \\
\hline 21. & I think I'm a good person & 1 & 2 & 3 & 4 & 5 & 6 \\
\hline 22. & I feel comfortable letting other people take control & 1 & 2 & 3 & 4 & 5 & 6 \\
\hline 23. & If I try hard, I can usually do well & 1 & 2 & 3 & 4 & 5 & 6 \\
\hline 24. & I can respond well to challenges & 1 & 2 & 3 & 4 & 5 & 6 \\
\hline 25. & I always try to think of what I can do to make things better & 1 & 2 & 3 & 4 & 5 & 6 \\
\hline 26. & Other people understand me & 1 & 2 & 3 & 4 & 5 & 6 \\
\hline
\end{tabular}




\begin{tabular}{|r|l|l|l|l|l|l|l|}
\hline 27. & I value many things about myself & 1 & 2 & 3 & 4 & 5 & 6 \\
\hline 28. & Other people have my best interest in mind & 1 & 2 & 3 & 4 & 5 & 6 \\
\hline 29. & 1 & 2 & 3 & 4 & 5 & 6 \\
\hline 30. & W do well when I try my best & 1 & 2 & 3 & 4 & 5 & 6 \\
\hline 31. & When things are bad I can still think of something good & 1 & 2 & 3 & 4 & 5 & 6 \\
\hline 32. & Other people care about me & 1 & 2 & 3 & 4 & 5 & 6 \\
\hline 33. & I value myself & 1 & 2 & 3 & 4 & 5 & 6 \\
\hline 34. & $\begin{array}{l}\text { I feel comfortable telling people important things about } \\
\text { myself }\end{array}$ & 1 & 2 & 3 & 4 & 5 & 6 \\
\hline 35. & If I try, I will succeed & 1 & 2 & 3 & 4 & 5 & 6 \\
\hline 36. & I can deal with tough things & 1 & 2 & 3 & 4 & 5 & 6 \\
\hline
\end{tabular}


Appendix B

Schema Questionnaire for Children

Instructions: Please read the following statements. To the right of each you will find six numbers, ranging from " 1 " (Completely untrue of me) on the left to "6" (Describes me perfectly) on the right. Choose the number which best indicates how much you believe each statement is true for you.

\begin{tabular}{|c|c|c|c|c|c|}
\hline 1 & 2 & 3 & 4 & 5 & 6 \\
\hline $\begin{array}{c}\text { Completely } \\
\text { untrue of me }\end{array}$ & & & & & $\begin{array}{c}\text { Describes me } \\
\text { perfectly }\end{array}$ \\
\hline
\end{tabular}

\begin{tabular}{|l|l|l|l|l|l|l|l|}
\hline 1 & $\begin{array}{l}\text { It is important to be better than others at } \\
\text { everything I do }\end{array}$ & 1 & 2 & 3 & 4 & 5 & 6 \\
\hline 2 & Other people are better than me & 1 & 2 & 3 & 4 & 5 & 6 \\
\hline 3 & No one loves or cares about me & 1 & 2 & 3 & 4 & 5 & 6 \\
\hline 4 & $\begin{array}{l}\text { It is important that my parents or caregivers } \\
\text { are involved in everything I do }\end{array}$ & 1 & 2 & 3 & 4 & 5 & 6 \\
\hline 5 & I am not responsible for what I do or say & 1 & 2 & 3 & 4 & 5 & 6 \\
\hline 6 & I am a failure & 1 & 2 & 3 & 4 & 5 & 6 \\
\hline 7 & I am more important and special than others & 1 & 2 & 3 & 4 & 5 & 6 \\
\hline 8 & $\begin{array}{l}\text { People will be cross or upset if I say the things } \\
\text { I really want to say }\end{array}$ & 1 & 2 & 3 & 4 & 5 & 6 \\
\hline 9 & I must not show my feelings to others & 1 & 2 & 3 & 4 & 5 & 6 \\
\hline 10 & $\begin{array}{l}\text { It is more important to put other people's } \\
\text { wishes and ideas before my own }\end{array}$ & 1 & 2 & 3 & 4 & 5 & 6 \\
\hline 11 & Others are out to get or hurt me & 1 & 2 & 3 & 4 & 5 & 6 \\
\hline 12 & No one understands me & 1 & 2 & 3 & 4 & 5 & 6 \\
\hline 13 & People I love will never be there for me & 1 & 2 & 3 & 4 & 5 & 6 \\
\hline 14 & I need other people to help me get by & 1 & 2 & 3 & 4 & 5 & 6 \\
\hline 15 & Bad things happen to me & 1 & 2 & 3 & 4 & 5 & 6 \\
\hline
\end{tabular}


Appendix C

MASQ-10

Instructions: This questionnaire asks you how you have been thinking, feeling or acting recently. For each item, please check the number that shows how often the statement is true for you. If a sentence is true about you a lot of the time, circle 3 . If it is true about you some of the time, circle 2 . If it is true about you once in a while, circle 1 . If a sentence is not ever true about you, circle 0 . Remember, there are no right or wrong answers, just answer how you have been feeling recently.

\begin{tabular}{|c|c|c|c|}
\hline 0 & 1 & 2 & 3 \\
\hline $\begin{array}{c}\text { Never true about } \\
\text { me }\end{array}$ & $\begin{array}{c}\text { Rarely true about } \\
\text { me }\end{array}$ & $\begin{array}{c}\text { Sometimes true } \\
\text { about me }\end{array}$ & $\begin{array}{c}\text { Often true } \\
\text { about me }\end{array}$ \\
\hline
\end{tabular}

\begin{tabular}{|l|l|l|l|l|}
\hline 1. The idea of going away to camp scares me & 0 & 1 & 2 & 3 \\
\hline $\begin{array}{l}\text { 2. I'm afraid that other kids will make fun of } \\
\text { me }\end{array}$ & 0 & 1 & 2 & 3 \\
\hline 3. I try to stay near my mom or dad & 0 & 1 & 2 & 3 \\
\hline 4. I get dizzy or faint feelings & 0 & 1 & 2 & 3 \\
\hline 5. I feel restless and on edge & 0 & 1 & 2 & 3 \\
\hline 6. I feel sick to my stomach & 0 & 1 & 2 & 3 \\
\hline 7. I get nervous if I have to perform in public & 0 & 1 & 2 & 3 \\
\hline $\begin{array}{l}\text { 8. Bad weather, the dark, heights, animals, or } \\
\text { bugs scare me }\end{array}$ & 0 & 1 & 2 & 3 \\
\hline 9. I check to make sure things are safe & 0 & 1 & 2 & 3 \\
\hline 10. I feel shy & 0 & 1 & 2 & 3 \\
\hline
\end{tabular}


Appendix D

CDI

Instructions. Kids sometimes have different feelings and ideas. This form lists the feelings and ideas in groups. From each group of three sentences, pick one sentence that describes you best for the past two weeks. After you pick a sentence from the first group, go on to the next group

1.

- I am sad once in a while. (0)

- I am sad many times. (1)

- I am sad all the time. (2)

2.

- Nothing will ever work out for me.

- I am not sure if things will work out for me.

- Things will work out for me O.K.

3.

- I do most things O.K.

- I do many things wrong.

- I do everything wrong.

4.

- I have fun in many things.

- I have fun in some things.

- Nothing is fun at all.

5.

- I am bad all the time.

- I am bad many times.

- I am bad once in a while.

6.

- I think about bad things happening to me once in a while. 
- I worry that bad things will happen to me.

- I am sure that terrible things will happen to me.

7.

- I hate myself.

- I do not like myself.

- I like myself.

8.

- All bad things are my fault.

- Many bad things are my fault.

- Bad things are not usually my fault.

9.

- I feel like crying every day.

- I feel like crying many days.

- I feel like crying once and a while.

10.

- Things bother me all the time.

- Things bother me many times.

- Things bother me once in a while.

11.

- I like being with people.

- I do not like being with people many times.

- I do not want to be with people at all.

12.

- I cannot make up my mind about things.

- It is hard to make up my mind about things.

- I make up my mind about things easily.

13.

- I look O.K.

- There are some bad things about my looks

- I look ugly 
14.

- I have to push myself all the time to do my schoolwork.

- I have to push myself many times to do my schoolwork.

- Doing schoolwork is not a big problem.

15.

- I have trouble sleeping every night.

- I have trouble sleeping many nights

- I sleep pretty well.

16.

- I am tired once in a while.

- I am tired many days.

- I am tired all the time.

17.

- Most days I do not feel like eating.

- Many days I do not feel like eating.

- I eat pretty well.

18.

- I do not worry about aches and pains.

- I worry about aches and pains many times.

- I worry about aches and pains all the time.

19.

- I do not feel alone.

- I feel alone many times.

- I feel alone all the time.

20.

- I never have fun at school.

- I have fun at school only once in a while.

- I have fun at school many times.

21. 
- I have plenty of friends.

- I have some friends but I wish I had more.

- I do not have any friends.

22.

- My schoolwork is alright.

- My schoolwork is not as good as before.

- I do very badly in subjects I used to be good in.

23.

- I can never be as good as other kids.

- I can be as good as other kids if I want to.

- I am just as good as other kids.

24.

- Nobody really loves me.

- I am not sure if anybody loves me.

- I am sure that somebody loves me.

25.

- I usually do what I am told.

- I do not do what I am told most times.

- I never do what I am told.

26.

- I get along with people.

- I get into fights many times.

- I get into fights all the time. 
Appendix E

The 14-Item Resilience Scale (RS-14)

Date

Please read the following statements. To the right of each you will find seven numbers, ranging from "1" (Strongly Disagree) on the left to "7" (Strongly Agree) on the right. Circle the number which best indicates your feelings about that statement. For example, if you strongly disagree with a statement, circle " 1 ". If you are neutral, circle " 4 ", and if you strongly agree, circle "7", etc.

\begin{tabular}{|l|l|l|l|l|l|l|l|l|}
\hline Circle the number in the appropriate column & \multicolumn{3}{|l|}{$\begin{array}{l}\text { Strongly } \\
\text { Disagree }\end{array}$} \\
\hline 1. I usually manage one way or another. & 1 & 2 & 3 & 4 & 5 & 6 & 7 \\
\hline $\begin{array}{l}\text { 2. I feel proud that I have accomplished things } \\
\text { in life. }\end{array}$ & 1 & 2 & 3 & 4 & 5 & 6 & 7 \\
\hline 3. I usually take things in stride. & 1 & 2 & 3 & 4 & 5 & 6 & 7 \\
\hline 4. I am friends with myself. & 1 & 2 & 3 & 4 & 5 & 6 & 7 \\
\hline $\begin{array}{l}\text { 5. I feel that I can handle many things at a } \\
\text { time. }\end{array}$ & 1 & 2 & 3 & 4 & 5 & 6 & 7 \\
\hline 6. I am determined. & 1 & 2 & 3 & 4 & 5 & 6 & 7 \\
\hline $\begin{array}{l}\text { 7. I can get through difficult times because I've } \\
\text { experienced difficulty before. }\end{array}$ & 1 & 2 & 3 & 4 & 5 & 6 & 7 \\
\hline 8. I have self-discipline. & 1 & 2 & 3 & 4 & 5 & 6 & 7 \\
\hline 9. I keep interested in things. & 1 & 2 & 3 & 4 & 5 & 6 & 7 \\
\hline 10. I can usually find something to laugh about. & 1 & 2 & 3 & 4 & 5 & 6 & 7 \\
\hline $\begin{array}{l}\text { 11. My belief in myself gets me through hard } \\
\text { times. }\end{array}$ & 1 & 2 & 3 & 4 & 5 & 6 & 7 \\
\hline $\begin{array}{l}\text { 12. In an emergency, I'm someone people can } \\
\text { generally rely on. }\end{array}$ & 1 & 2 & 3 & 4 & 5 & 6 & 7 \\
\hline 13. My life has meaning. & 1 & 2 & 3 & 4 & 5 & 6 & 7 \\
\hline $\begin{array}{l}\text { 14. When I'm in a difficult situation, I can } \\
\text { usually find my way out of it. }\end{array}$ & 1 & 2 & 3 & 4 & 5 & 6 & 7 \\
\hline
\end{tabular}

(C2009 Gail M. Wagnild and Heather M. Young. Used by permission. All rights reserved. "The Resilience Scale" is an international trademark of Gail M. Wagnild \& Heather M. Young, 1993 
Appendix F

Consent form

\section{UNIVERSITY}

COLLEGE OF SOCIAL AND APPLIED HUMAN SCIENCES

Department of Psychology

Parent/ Legal Guardian Information and Consent Form

Building Healthy Relationships Project:

Dr. Karl Hennig

Department of Psychology

voice: (519) 824-4120 ext. 53558

fax: (519) 837-8629 email:

khennig@uoguelph.ca

\author{
Dr. Margaret Lumley \\ Department of Psychology \\ voice: (519) $824-4120$ ext. 56798 \\ fax: (519) 837-8629 e- \\ mail:mlumley@uoguelph.ca
}

Introduction: Youth and their parents are concerned about personal and interpersonal problems children experience as they grow up. As you likely know, these problems may have a strong negative effect on how well children do in school, socially, and later in life. The Wellington Catholic District School Board in conjunction with the University of Guelph will be administering a pilot curriculum program addressing peer-relationship challenges associated with middle childhood and early adolescence. The current research project is to help us to understand the difficulties that youth report facing. Results will be used to inform our understanding of personal and interpersonal problems and to inform future school programs.

Procedure: We are asking that parents give permission for their youth to complete a confidential questionnaire package, which will be completed on-line during one regular class block. The questionnaire package inquires about problems as well as strengths, including questions about self-esteem (e.g., "I am a good friend") and wellbeing (e.g., "How happy do you feel?" "How worried are you?" "How often do you do what you are told?", "My mother makes me feel better after talking over my worries with me"). To gain an additional perspective, we would request that you as the parent/legal guardian complete a brief 1-page questionnaire. Within the next year or so, we would also like repeat the study and we additionally request your consent to contact you in the future to invite your youth's participation in this optional follow-up component of the project. There are no known physical or social risks of participating in this research. Questions about self-esteem and wellbeing might upset some children, however, we believe this risk is minimal given the child-friendly approach of our research team and the measures that we use. In our experience, young people have enjoyed participating in similar projects, however, participating in this study may not directly benefit your child. Children will be 
offered an edible treat or yo-yo to thank them for their participation. Parents who return the questionnaire will be entered into a draw to win one of five $\$ 30.00$ gift certificates.

Your child will be told that he or she has a choice whether or not to participate and will also be told that he or she may withdraw from the study or choose not to answer a particular question at any time, without penalty. Withdrawal or refusal to answer questions will not influence any privileges or resources that your child receives from the school. If students withdraw, their data will be destroyed.

Confidentiality: We will be collecting identifying information on the youth, but such information will not be attached to the other measures completed. All information provided is strictly confidential and will be used for research purposes. We will store the data files indefinitely for future analysis. With one exception, schools will not have access to any information we collect. In the event that a youth reports significant distress or anger/aggressiveness, we will follow-up to contact you as a parent/guardian and the school to discuss what resources there are to assist the youth. We will also be providing school personnel and interested parents with the major results of the study at an information night. Like you, we are interested in the wellbeing of youth and helping them to succeed personally, socially, and academically.

This project has been reviewed and received ethics clearance by the Research Ethics Board of the University of Guelph and the Wellington Catholic District School Board (WCDSB). If you have any questions or concerns regarding your family's rights or treatment as participant(s) in the project, you may contact Sandy Auld in the Research Ethics Board at the University of Guelph at 519-824-4120 ext.56606 (reb@uoguelph.ca), or Dr. Karl Hennig and Dr. Margaret Lumley, whose contact information is listed above.

\section{CONSENT FORM: BUILDING HEALTHY RELATIONSHIPS PROJECT}

\section{Please return to your child's classroom teacher}

I (the parent/guardian) consent to my son/daughter's participation in the "Building Healthy Relationships Project"

I (the parent/guardian) agree to complete a brief 1-page questionnaire.

I (the parent/guardian) consent to University researchers contacting us to invite participation in the 1-year optional follow-up component of the study.

Child's teacher:

(Child's name: Please Print)

(Parent/ Legal Guardian Name and Signature)

(Date) 
Child's Date of Birth:

up invite - OPTIONAL)
Your phone \#: (for the 1-year follow- 